\title{
An infectious virus-like particle built on a programmable
}

\section{icosahedral DNA framework}

\author{
Yunyun $\mathrm{Xu}^{1}$, Yuhe R. Yang ${ }^{2,3}$, Qian Shi ${ }^{1}$, Andrew B. Ward ${ }^{3}$, Wei Wang ${ }^{1}$, Yang Yang ${ }^{1 *}$ \\ ${ }^{1}$ Institute of Molecular Medicine and Shanghai Key Laboratory for Nucleic Acid Chemistry and \\ Nanomedicine, State Key Laboratory of Oncogenes and Related Genes, Renji Hospital, School of \\ Medicine, Shanghai Jiao Tong University, Shanghai, 200127, China. \\ ${ }^{2}$ National Center for Nanoscience and Technology, Chinese Academy of Sciences, Beijing, 100190, \\ China \\ ${ }^{3}$ Department of Integrative Structural and Computational Biology, The Scripps Research Institute, \\ La Jolla, CA 92037 \\ * Correspondence to: Yang.yang.nano@sjtu.edu.cn ORCID: 0000-0002-2630-6062
}

\begin{abstract}
Viral genomes can be compressed into a near spherical nanochamber to form infected particles. In order to mimic the virus morphology and packaging behavior, we invented a programmable icosahedral DNA nanoframe with enhanced rigidity and encapsulated the phiX174 bacteriophage genome. The packaging efficiency could be modulated through specific anchoring strands adjustment, and the enveloped phage genome remained accessible for enzymatic operations. Moreover, the packed complex could infect $E$. coli cells through bacterial uptake then produce plaques. This rigid icosahedral DNA architecture established a versatile platform to develop virus mimetic particles for convenient nucleic acid entrapment, manipulation and delivery.
\end{abstract}

\section{Introduction}

As the simplest "being", virus, composed by nucleic acids, proteins and sometimes lipids, is considered an inevitable object in the path of understanding and defining life. Conventional microbiology, virology and molecular biology have paved the road of how to investigate viruses $^{1}$, meanwhile bioengineering has developed several neat and powerful tools to equip and utilize viruses (adenovirus vectors ${ }^{2}$, phage display technology ${ }^{3,4}$, phage therapy ${ }^{5}$, etc.), yet the mysteries and values of viruses haven't been fully explored. The flourishing field of structural DNA nanotechnology offers strategies to assemble customized structures and organize individual molecules or particles with nanometer precision ${ }^{6,7,8}$. Besides employing DNA nanodevices to mimic $^{9,10}$ or capture virus particles ${ }^{11}$, a few examples have revealed that DNA nanostructures were competent in displaying and regulating viral proteins to study their assembly, infection efficiency and antigen induced immunity $12,13,14,15$. These attempts suggest the opportunity of using artificial tools to dissect viruses, reorganize the components, investigate their behavior, functions and related biological mechanisms, and construct novel nano-devices for biomedical applications.

Among the critical processes in the virus life cycle (e.g. infection, replication, packaging and releasing), packaging as the last step of morphogenesis allows the maturation of the virion through protein-nucleotides interaction and end up with the micrometer long nucleic acid 
winding inside a zeptoliter $\left(10^{-12}\right.$ nanoliter) tiny space ${ }^{16}$. Taking the well-studied ssDNA phage phiX174 as an example, along with the genome replication process, the $5386 \mathrm{nt}$ ssDNA would recruit 60 copies of protein $\mathrm{J}$, which is highly basic, to neutralize the charge and enter the procapsid ${ }^{17}, 18$. As a result, the phiX174 genome is packed inside the virion particle with a portion $(8 \% \sim 10 \%)$ of nucleotides immobilized in an icosahedral order at the inner surface of the protein shell19, 20 . Acknowledging that the sophisticated near-spherical geometry and the inner decoration sites are key features of the virion for genome packaging during the matruation ${ }^{21}$, we aim to manufacture an artificial DNA nanostructure to mimic the phiX174 packaging, explore strategies to densely load viral genome inside the structure and regulate the critical parameters of this process, and further polish the phage mimetic device for nucleic acid entrapment, engineering and delivery.

In this study, we constructed a rigid icosahedral DNA origami framework, equipped its inner surface with sufficient number of anchors, and enveloped the phiX174 genome inside the origami frame. The conditions for efficient packaging were systematically elaborated. We demonstrated that the hollow particle with regularly carved surface allowed the free entrance of enzymes to conduct molecular operations on the packed ssDNA. We further discovered that this mimetic complex solely composed of nucleic acid could passively infect the noncompetent $E$. coli cells through bacterial uptake. The viral genome packaging strategy and the achieved phage mimetic nano device offers the opportunities for convenient phage engineering and delivery, which suggested multiple potentials in developing pseudo-phage therapy and nucleic acid vaccines. Meanwhile, the rigid and reliable icosahedral framework establishes a versatile platform that can be precisely functionalized, both inside and outside, to satisfy biochemical or biomedical researches with optimum modification and modulation.

\section{Results}

\section{Nano frame assembly and ssDNA packaging}

The icosahedral DNA origami frame (IDF) structure is designed via an open source software Tiamat. The IDF assembly is consist of a $7560 \mathrm{nt}$ circular ssDNA scaffold which sequesters 216 staple strands (a.k.a. staples). The two dimensional (2D) blue print of the IDF illustrates the 30 edges of the icosahedron in an unfolded state (see Supplementary Figure 1). Each of the edge is designed as a four helix bundle with 63 nucleotides $(\sim 21 \mathrm{~nm})$ in length. The four helices are considered as two layers of double-helix module, a foundation layer $(F L)$ and an addition layer (AL). Scaffold strand at the foundation layer is applied to connect adjacent edges and route through the icosahedral frame, while a $126 \mathrm{nt}$ scaffold loop protrudes from each edge and forms the addition layer with the assistance of staples (see Supplementary Figure 2). The IDF structure was successfully assembled through a 15 hour annealing program and purified with a rate-zonal gradient ultracentrifugation $\mathrm{ste}^{22}$. The products were characterized by agarose gel electrophoresis (AGE) and negatively stained Transmission Electron Microscopy (nsTEM) (see Supplementary Figure 3). Structure models and representative nsTEM images of the natural phiX174 phage ${ }^{20}$, the ssDNA genome, and the fabricated IDF structure were exhibited side by side in Figure $1 \mathrm{a}$ and $1 \mathrm{~b}$. The outstanding integrity and homogeneity of our IDF structure were attributed to the strengthened rigidity of the four helix bundle edges comparing to the 2 and 1 helix design published previously ${ }^{13,23,24,25}$. The 
topology of the IDF structure was further investigated through an orthogonal dimerization assay, in which, a pair of strands (termed a and a') with complementary sequences were protruded from either the foundation layer or the addition layer on one edge of the IDF. By mixing the four types of monomer structure (termed FL-a, FL-a', AL-a and AL-a') with one another, the clearly increased dimer bind intensity was observed only in the FL-a/FL-a' sample from the AGE image (see Supplementary Figure 4), which demonstrated that the IDF had its foundation layer facing outward and the addition layer facing inward. The two distinguishable faces are considered to be a result from the modified spacer at the vertices, compared to the previous design ${ }^{26}$. The staples crossing neighboring edges are linked by a $5 \mathrm{~T}$ spacer $(5 \mathrm{nt}$ polyT loop) in the foundation layer while a 1T spacer is introduced to the edge-crossing staples at the addition layer (see Figure $1 \mathrm{~b}$ and Supplementary Figure 2). The slight differences in tension accumulated around the vertices between two layers determines the unidirectional folding of the structure. Thus, modifications on the inner or outer surface of the IDF can be distinguished and controlled.

a
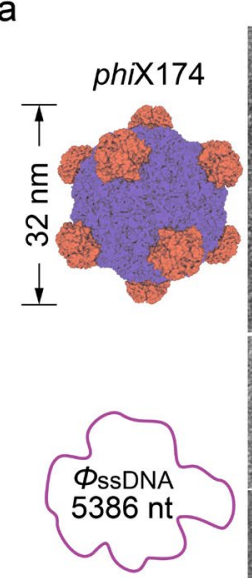

C

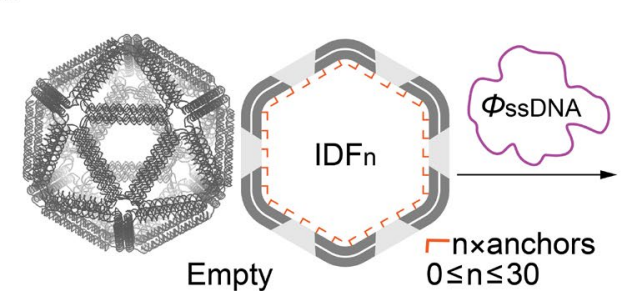

b
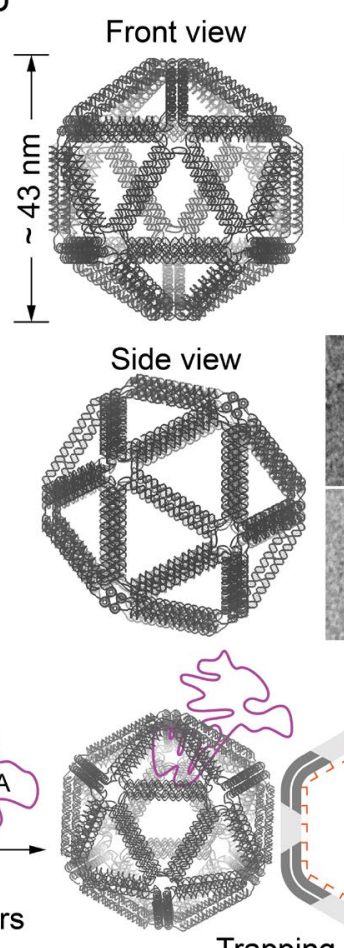
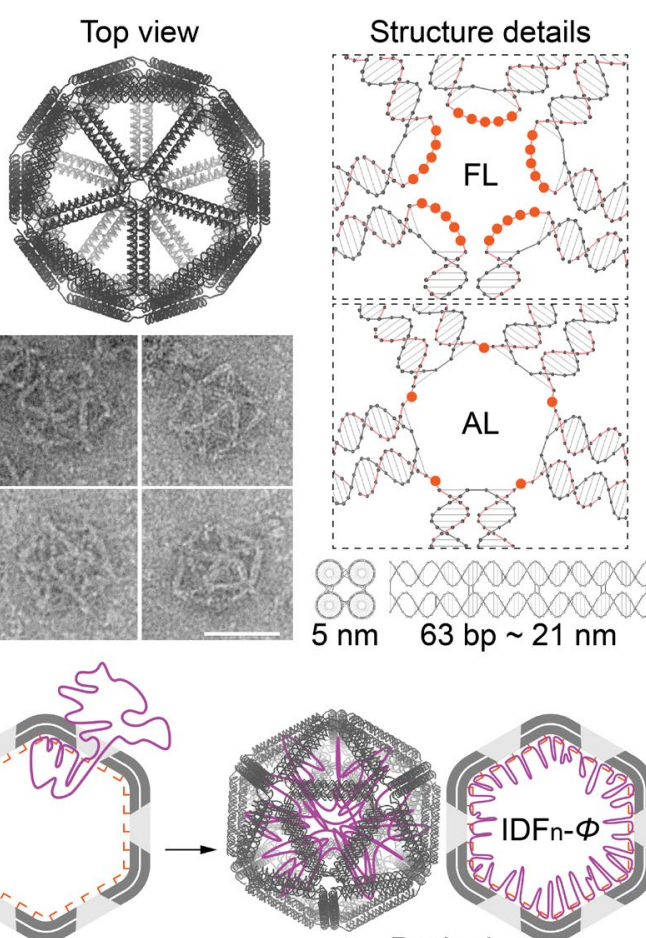

smm

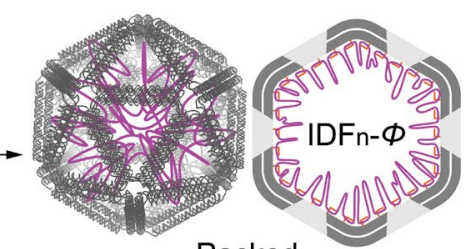

Packed

Figure 1. a. Structure mode ${ }^{20}$ and representative nsTEM images of the phiX174 phage particle and its ssDNA genome. b. Multi-view schemes of the IDF 3D model, representative nsTEM images of the assembled structure, and details of the IDF vertex (at both foundation layer and addition layer, each orange dot represented a $\mathrm{T}$ base) and edge. c. Hypothesized IDF induced phiX174 genome packaging process. Scale bar: $50 \mathrm{~nm}$.

Next, the circular 5386 nt phiX174 genome $\left(\Phi_{\text {ssDNA }}\right)$ to be packaged inside the IDF nanoparticle was evenly divided into 30 fragments $(29 \times 180 \mathrm{nt}+1 \times 166 \mathrm{nt})$, and the starting 10-30 nt of each section was chosen to be the anchoring site. Accordingly, the 30 edges of the IDF were re-assigned in an order following the Eulerian path with the shortest neighboring distance (see Supplementary Figure 5), thus 30 specific anchor sequences (complementary to the anchoring sites of the $\Phi_{\mathrm{sSDNA}}$ ) were sequentially allocated to the edges and protruded 
from the addition layer towards the inner space of the IDF. As hypothesized in Figure 1c, once the $\Phi_{\text {SSDNA }}$ was mixed with the fully decorated icosahedron (termed IDF 30 ), the $\Phi_{\text {ssDNA }}$ might occasionally and partially stretch into the IDF from the triangular windows and get immobilized by the closest anchor strand with complementary sequence. Nucleated by the anchored sites, the probability of the anchoring events at the adjacent sites would be greatly increased due to the improved proximity between the anchors and their targeted segments. After a "dominolike" anchoring reaction, the whole genome was absorbed into the frame and fully packed as a nano complex $\mathrm{IDF}_{30}-\Phi$.

Considering the $\mathrm{IDF}_{30}$ as an enthalpy trap, the packaging efficiency would rely on the binding energy and kinetics, which resulted from the length of the anchor strands and the incubation conditions. By adjusting the anchor strand length from 10, 20 to $30 \mathrm{nt}$, three versions of IDF 30 (e.g. IDF $_{30}-10 \mathrm{nt}$, -20nt, -30nt) were mixed with $\Phi_{\mathrm{ssDNA}}$ at ratio $1: 1$ or $1: 5$ and incubated at different temperatures (e.g. room temperature $\sim 23^{\circ} \mathrm{C}, 42^{\circ} \mathrm{C}$ and $50^{\circ} \mathrm{C}$ ) for the same amount of time (15 hrs). Results from the AGE analysis (see Supplementary Figure 6) suggested that the $10 \mathrm{nt}$ anchor design was not strong enough to introduce or maintain the association between the $\Phi_{\text {sSDNA }}$ and the IDF 30 , while frames with anchor length longer than 20 nt were sufficient in yielding products with slower mobility, moreover, higher temperatures would benefit the productivity. At 1:1 ratio, an emerged clear single band suggested a distinct product formation of IDF and $\Phi_{\text {ssDNA }}$ complex. An extra band and darker smears were observed at 1:5 ratio, which indicates dual or multiple ssDNA associated IDFs. Therefore, IDF 30 -20nt was used to trap a $\Phi_{\text {sSDNA }}$ following the optimized protocol (see Supplementary Figure 6 and Methods section) in the following studies.

As shown in Figure $2 a$, the bare IDF without anchors $\left(I^{2} F_{0}\right)$ could hardly associate with $\Phi_{\text {ssDNA. }}$. In contrast, the IDF $_{30}-20$ nt bound with $\Phi_{\text {sSDNA }}$ equivalently and efficiently, no further purification was performed. The achieved product IDF ${ }_{30}-\Phi$ was subjected to nsTEM and Cryo-EM imaging (see Figure $2 \mathrm{~b}$ and Supplementary Figure 7 ). From both type of EM images, IDF I0- $\Phi$ particles presented sharp and clear boundaries, similar to the bare IDF $_{30}$, but cloudier inner spaces. Single particle analysis (SPA) of the cryo-EM data provided higher resolution comparison of the empty and stuffed icosahedron frame with $2 \mathrm{D}$ classification and $3 \mathrm{D}$ reconstruction. Both the global and cross-section profiles of the $3 \mathrm{D}$ reconstruction of $\mathrm{IDF}_{30}-\Phi$ exhibited extra interior electron density compared to the empty reference, which strongly suggested the successful packaging of $\Phi_{\text {ssDNA }}$ as hypothesized in Figure 1c. Moreover, the exterior of IDF ${ }_{30}-\Phi$ and IDF 30 provided equal level of electron density even at low threshold of the cryo-EM density maps (see Supplementary Figure 8 ). This observation indicated that the majority of $\phi_{\text {SSDNA }}$ was trapped inside the IDF periphery, which could be attributed to the $\mathrm{Mg}^{2+}$ mediated charge neutralization and the intrinsic polymer properties of ssDNA (highly curled due to very short persistence length and end-to-end distance) ${ }^{27,28}$. Furthermore, direct particle size measurement of the nsTEM images (EMI) and dynamic light scattering (DLS) analysis both proved that the particle sizes of $I^{D} F_{30}$ rarely changed after the packaging (see Figure $2 \mathrm{c}$ ), which recurrently verified the outstanding rigidity of the IDF. 
a

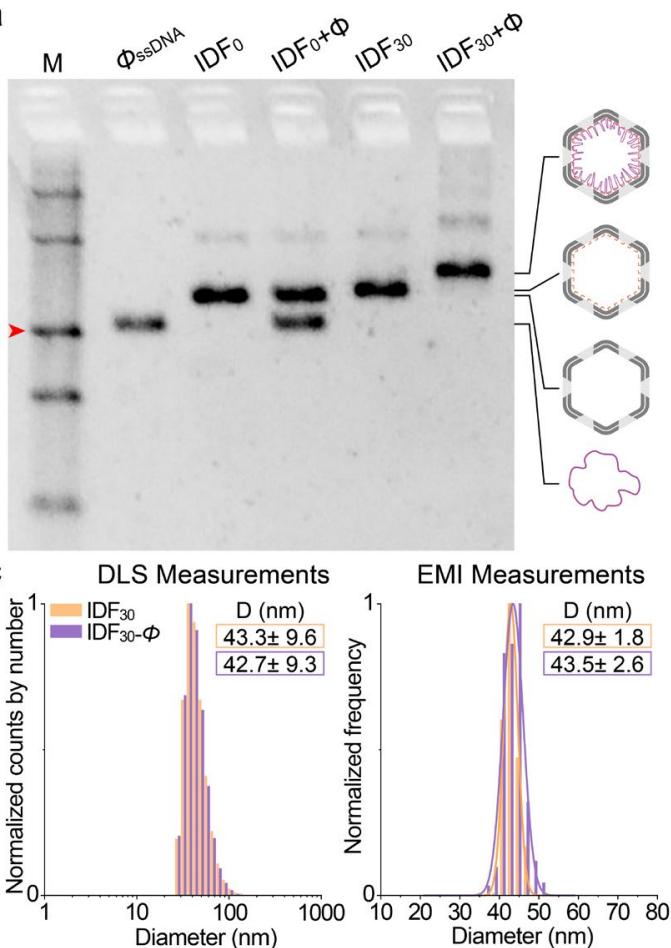

b

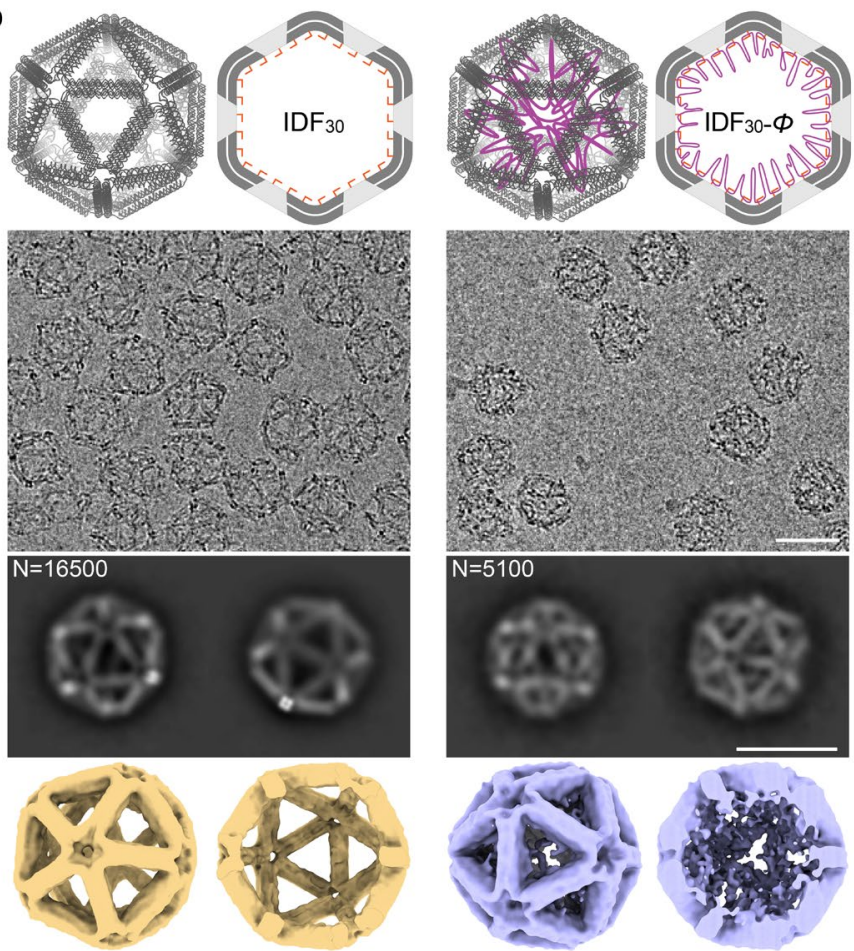

Figure 2. Characterization of ssDNA packaging. a. $\Phi_{\mathrm{ssDNA}}, \mathrm{IDF}_{0}, \mathrm{IDF}_{30}$ and the products of $\left(\mathrm{IDF}_{0 \text { or } 30}+\Phi_{\mathrm{SSDNA}}\right)$ incubation characterized by agarose gel electrophoresis (1.5\% AGE, 60V, 120 min, stained by GelRed; red arrow indicated the 1500 bp DNA marker band). b. CryoEM characterization of empty $\mathrm{IDF}_{30}$ particles and packed $\mathrm{IDF}_{30}-\Phi$ complexes. $1^{\text {st }}$ row: structure schemes; $2^{\text {nd }}$ row: raw micrographs; $3^{\text {rd }}$ row: representative images of the $2 \mathrm{D}$ classes and $4^{\text {th }}$ row: 3D reconstruction results shown in global and cross-section mode. Scale bar: $50 \mathrm{~nm}$. c. Statistics of the particle sizes from both dynamic light scattering analysis and electron microscopy imaging measurements.

To systematically investigate the packaging behavior, the number and position of anchor strands inside the IDF were precisely altered, taking the advantage of the full addressability of DNA origami structures ${ }^{29}$. IDFs with 18 and 6 anchors (named IDF 18 and IDF 6 ) targeting evenly spaced segments of the $\Phi_{\text {SSDNA }}$ were assembled and examined by AGE (see Figure 3a). Band intensity analysis revealed that $I_{18}$ packed $\Phi_{\text {ssDNA }}$ with $99.3 \%$ efficiency, whereas $I_{1 D F_{6}}$ showed a slightly lower binding efficiency $(91 \%)$ with two faint bands corresponding to the leftover IDF origami particles and ssDNAs. Interestingly, when 12 and 24 complementary strands (CS) with 20 nt nucleotides each were co-assembled with $I_{12 F_{18}-} \Phi$ and $I D F_{6}-\Phi$ to compensate the anchor-missing segments along the $\Phi_{\mathrm{ssDNA}}$, the packing efficiencies could be recovered to near $100 \%$ and $93.2 \%$, respectively. The visibly lagged IDF $_{6}-\Phi$ band (compare to $I D F_{30} \Phi$ in the AGE gel image) indicated a less compact product, potentially due to the fact that the six long unbound ssDNA segments ( $880 \mathrm{nt}$ each) had higher chance to drift out of the frame which resulted in a slower mobility in the gel. Moreover, an IDF with only the front 10 anchors $\left(I^{D} F_{10}\right)$ targeting $1 / 3$ of the $\Phi_{\text {SSDNA }}$ in an unbalanced distribution was assembled to test whether a partially packed product could be generated. The AGE analysis indicated that $I D F_{10}$ and $\Phi_{\text {sSDNA }}$ also yielded a one-to-one associated complex with slower mobility and lower efficiency (similar to $I^{2} F_{6}-\Phi$ ) than $I D F_{30} \Phi$ (see Figure $3 b$ ). Meanwhile, TEM images denoted that the $I D F_{10^{-}} \Phi$ particles possessed a curled thread (ssDNA) tangling around the icosahedron, 
which strongly supported the proposed packaging mechanism shown in Figure 1c.

a

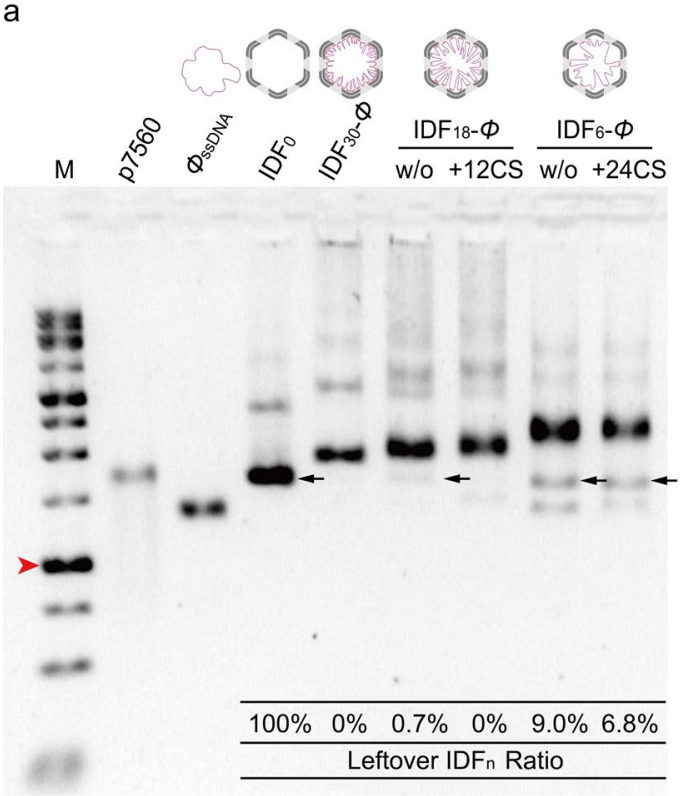

b

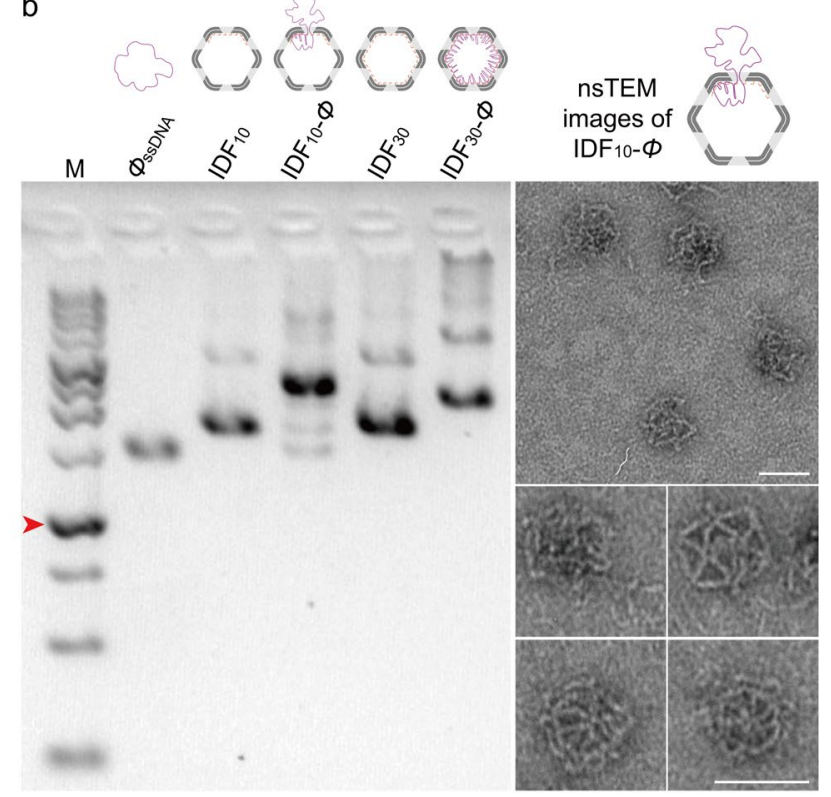

Figure 3. Packaging behavior modulation. a. AGE analysis of packaging products from IDF structures with 30,18 or 6 evenly spaced anchoring strands, with or without compensate ssDNA oligos. Black arrows indicated the unpacked (leftover) $I_{D F}$ shells, and the ratio comparing to the starting material were calculated and listed at the bottom. b. AGE and nsTEM characterization of the IDF 10 (continuously arranged instead of evenly spaced anchor strands) and $\Phi_{\text {SSDNA }}$ association. Red arrow indicated the 1000 bp DNA marker band. Scale bar: $50 \mathrm{~nm}$.

Inner space accessibility and molecular operation

Different from the natural bacteriophage phiX174, whose genome is protected by the compact capsid with tightly assembled scaffold proteins, the inner space of the artificial IDF ${ }_{n}-\Phi$ complex is accessible through the twenty regular triangle windows with $21 \mathrm{~nm}$ edge length. Thus, enzymatic reactions targeting the packed ssDNA are permitted. We first employed an ssDNA specific endonuclease, Mung bean nuclease (MBN), and tested whether it could enter IDF ${ }_{30^{-}}$ $\Phi$ and digest the tethered $\Phi_{\text {sSDNA. }}$. AGE results clearly demonstrated that the molecular weight of IDF $30-\Phi$ gradually decreased after the MBN treatment and reached the IDF 30 level within 30 min digestion (see Figure $4 a$ ), indicating full digestion of the packaged $\Phi_{\text {ssDNA. While }}$ unpckaged free $\Phi_{\text {SSDNA }}$ was chopped into pieces in only $5 \mathrm{~min}$ at the same condition. Similar results were observed with P1 nuclease (see Supplementary Figure 9). Secondly, a classic rolling circle amplification (RCA) reaction using the packaged phiX174 circular SsDNA as templates was performed. Once the phi29 DNA polymerase and dNTP were mixed with IDF ${ }_{30^{-}}$ $\Phi$ without the participation of additional primers, high molecular weight products were accumulated which stuck in the wells in AGE, along with the reduced band intensity of IDF ${ }_{30}$ $\Phi$. Samples after one-hour RCA reaction were examined by TEM, long ssDNA spread out of each icosahedron and mostly tangled into aggregates (see Figure $4 \mathrm{~b}$ ) were observed. Comparing to the free $\Phi_{\text {SSDNA }}$ templated RCA with 30 primers (20 nt each with the same 
sequences of the anchor strands) included, where $\Phi_{\text {sSDNA }}$ was completely consumed in half an hour, the $I D F_{30^{-}} \Phi$ was hardly exhausted in two hours. Therefore, it was convincing that the IDF packed ssDNA was accessible to other molecules in circumstances, but the enzymatic reactions were slowed down since diffusion of materials were likely to be limited with the DNA origami frame. Additionally, the operational RCA without additional primers indicated that the thirty anchor strands with available 3' hydroxide group would work as primers to amplify along the trapped $\Phi_{\mathrm{SSDNA}}$ template, thus changing the number of anchor strands might result differently. To confirm this, IDF ${ }_{18}-\Phi$ and $I D_{6} 6^{-} \Phi$ were applied to the RCA system, and it was obvious that the IDF particle with fewer anchors yielded more leftover structures after the twohour reaction. Moreover, 12 and 24 extra primers were introduced to compensate the IDF $18^{-}$ $\Phi$ and IDF $_{6}-\Phi$ complexes, respectively, for a total 30-primers formation, which recovered the 219 RCA reaction with much less leftover products (see Supplementary Figure 10).

a

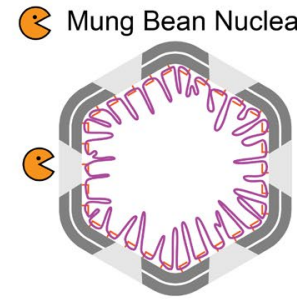

b O phi29 DNA polymerase

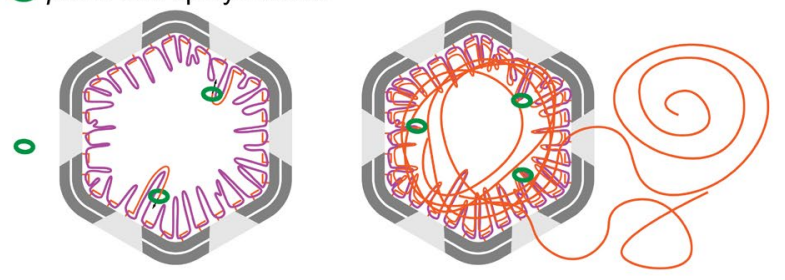

$Q^{x^{3}} \quad \mathrm{IDF}_{30}-\Phi+\mathrm{MBN}$

M
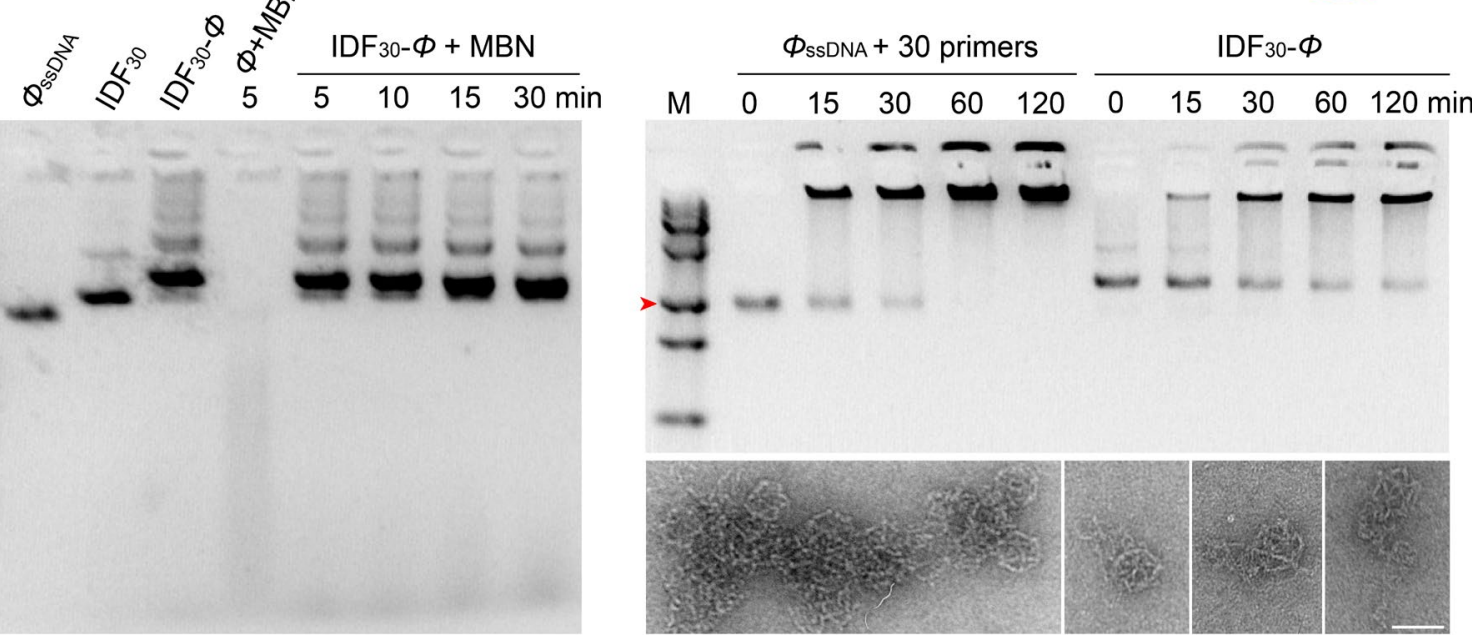

Figure 4. Accessible enzymatic reaction assays. a. scheme and AGE analysis of the MBN induced ssDNA digestion for both naked and packed phiX174 genome (red arrow indicates the 1000 bp DNA marker band). b. scheme and AGE analysis of the phi29 DNA polymerase induced RCA reaction (red arrow indicates the $1500 \mathrm{bp}$ DNA marker band). Note that for naked $\Phi_{\text {sSDNA }}, 30$ primers targeting the exact anchoring sites were added in 1:1 stoichiometry, while for $I D F_{30} \Phi$, no primers was involved. nsTEM images of the $I D F_{30}-\Phi$ sample after 60 min reaction were shown at the bottom row. Scale bar: $50 \mathrm{~nm}$.

Host cell uptake induced passive infection

Although phiX174 genome was successfully packed in the artificial DNA nano frame in an icosahedral manner, the natural capability of phage infection was not expected to be inherited by the $I \mathrm{FF}_{\mathrm{n}}-\Phi$ complexes, in lack of the crucial protein components, such as the spike protein $\mathrm{G}$ and $\mathrm{H}^{16,30}$. However, in attempts to verify the above prediction, significant amount of plaques were observed, surprisingly, upon mixing of $E$. coli $C$ (a phiX174 sensitive strain of $E$. coli) with 
$\mathrm{IDF}_{30}-\Phi$ and cultured on agar plates, following the phage plaque assay protocol ${ }^{31,32}$ (see Methods section). It was noticeable that the plaque was only observed after 6 hours culturing at $37{ }^{\circ} \mathrm{C}$, which was much slower than the natural phiX174 infection ${ }^{32}$ (normally 1 2 hours, see Supplementary Figure 11). This phenomenon was repeatedly confirmed, and the number of plaques followed a linear relationship with the $\operatorname{IDF}_{30}-\Phi$ amount that was mixed with the cell, which led to a particle to plaque forming unit (pfu) ratio of $7.5 \times 10^{6}$ (See Supplementary Figure 12). The IDF particle could deliver the phiX174 genome into the bacteria cytoplasm; therefore direct the progress of real phage particle production and bacteria lysis. Whereas, comparing to the natural bacteriophage infection, whose particle to pfu ratio was normally close to one ${ }^{33}$, the millions of times weaker $I D F_{30} \Phi$ "infection" suggested a diverging internalization path. Meanwhile, the way of competent cell transformation was excluded, since the $E$. coli cells were treated at mid-log phase $\left(\mathrm{OD}_{600}\right.$ at $\left.0.2 \sim 0.8\right)$ without stimulation of electricity, bivalent cation, osmotic shock or heat shock ${ }^{34}$. Assuming that this passive infection process could be affected by the DNA to $E$. coli affinity, a few strategies aiming at modifying the IDF structure to improve the bacteria attachment were tested. By introducing oligolysine $\left(K_{n}, n=6,8\right.$, or 10) and polyethylene glycol conjugated oligolysine $\left(P E G_{1 K}-K_{6}\right)$ to the $I D F_{30}-\Phi$ to change its overall static potential ${ }^{35}$, or by extending thirty DNA aptamer strands targeting $E$. coli ${ }^{36}$ at the IDF $_{30}-\Phi$ outer surface to induce specific attachment, a vague hint of increased infection was observed (see Supplementary Figure 13), but solid conclusions could hardly be derived.

To better discover this mystery, a series of $I D F_{n}-\Phi$ complexes $(n=6,18$ and 30 ) were compared in parallel together with the naked $\Phi_{\mathrm{ssDNA}}$. Keeping the amount of added genome in constant (either packed or naked), the complex with more anchors generated more plaques in each trail, while the naked ssDNA accidentally resulted a few plaques (photos of a representative trail were shown in Figure 5a). To eliminate batch-to-batch differences, the counted plaque numbers were normalized by the $I F_{30}-\Phi$ group in each trail and plotted with box analysis as shown in Figure 5b (see original data of each trial in Supplementary Figure 14). The trend of anchor number dependent plaque growth evidenced an essential role of the hybridized segments in the phage production process.

Based on the observations above, a possible scenario with detailed assumptions were stated as follows. Firstly, nucleic acid materials could enter the $E$. coli cytoplasm through cell uptake in a small but existing odds (comparing to competent cell transformation). As reported, in some naturally competent gram-negative bacteria species, the transformation of environmental dsDNA required particular pilus and associated transformation proteins to capture, predigest and transport the exogenous DNA $37,38,39$. Here, the assembled IDF particle probably entered the cell through different pathways, because the large size, particular geometry and high rigidity could hardly adapt to the transformation protein initiated internalization mechanism. Secondly, the IDF cage including the anchors might have helped the enveloped ssDNA bypass the immune (in other word, self-protection) system of $E$. coli via screening or delaying the associated enzymatic digestion. Thirdly, the internalized IDF particle allowed the entrance of bacterial DNA/RNA polymerase to accomplish the phiX174 mRNA transcription and genome amplification in a slower pace. Finally yet importantly, the anchor strands were believed participating the replication of the phage genome. The natural phiX174 genome replication were known to start with a discontinuously synthesis of the complementary (anti-sense) strand 
to achieve a replicative form (RF) dsDNA, followed with a two-directional replication, and numerous gaps were reported existing on the complementary strand of the RF II molecules (nicking form vs. the supercoiled RF I form ${ }^{40}$. Therefore, the IDF packed phiX174 genome with partially hybridized segments (with free 3' ends) unintentionally matched the pattern of the natural RF II DNA, and resulted the anchor number dependent plaque emergence. The proposed $E$. coli uptake induced passive infection process was shown in Figure $5 c$.
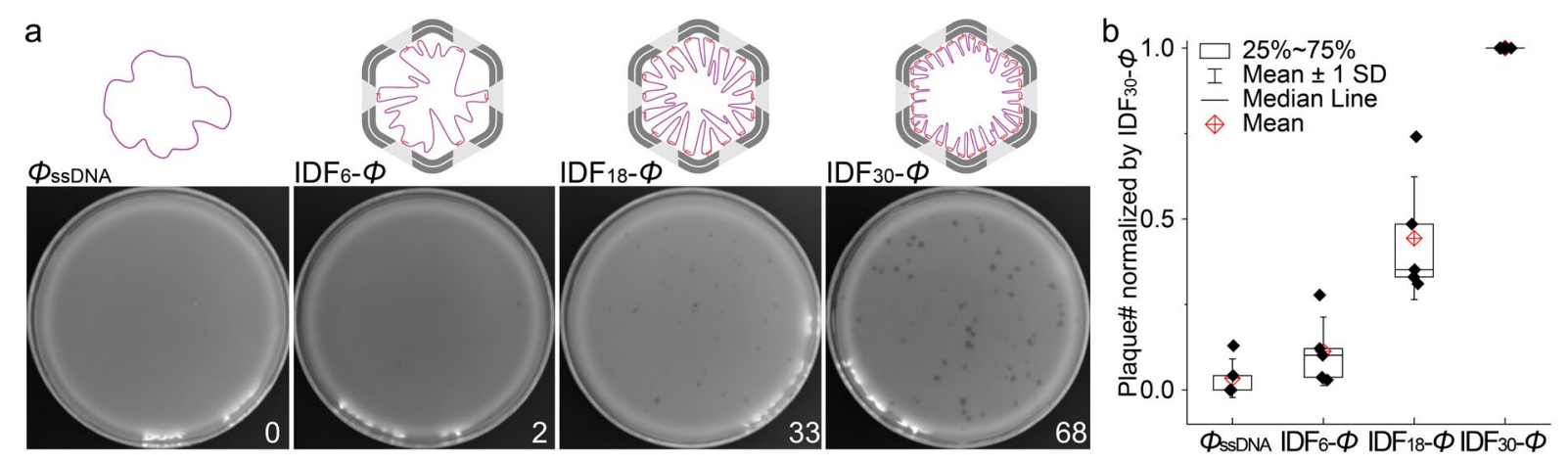

c

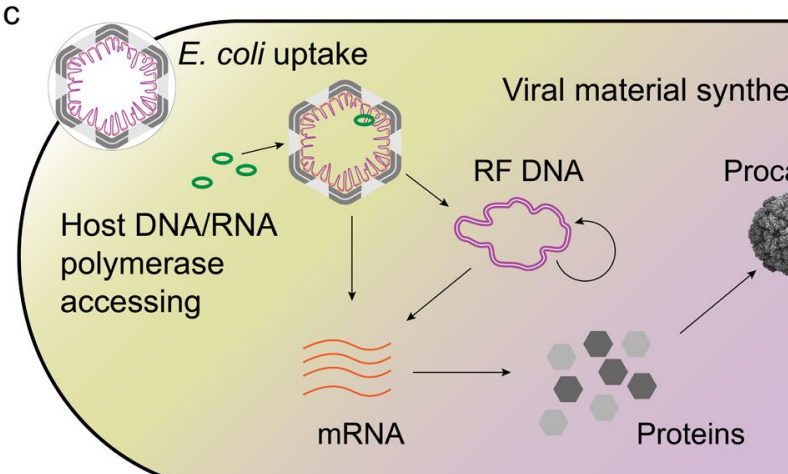

\begin{abstract}
is
\end{abstract}
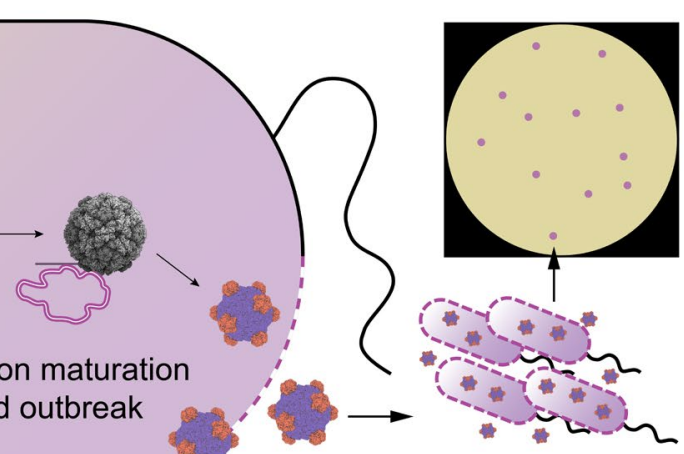

Cell lysis and plaque forming

Figure 5. Mimetic particle infection study. a. a representative trail of plaque assay using naked or IDFn ( $n=6,18$ or 30$)$ packed form of $\Phi_{\text {sSDNA }}$ to co-culture with $E$. coli $C$ on arga plates. b. statistical analysis of five repeated trails of the plaque assay (original images and data shown in Supplementary Figure 15). c. Schematics of the proposed passive infection process initiated by bacterial uptake.

\title{
Discussion
}

As a general strategy, viral genome, the highly negatively charged DNA or RNA, could be packed into a near spherical protein shell nano compartment to form the infectious particle. One of the well-studied icosahedral fashioned virus nanoparticle is the bacteriophage phiX174. To mimic the phage morphology and packaging behavior, a de novel designed icosahedral DNA frame with reinforced rigidity was assembled. The direction of the folding is controlled with the unique two-layer design with different loop length at the vertices of each layer, therefore specific modification at either inner or outer surface has been achieved. By utilizing programmed anchoring strands that display over the inner surface of the IDF, the circular 5386nt natural phiX174 genome was efficiently packed into the DNA origami frame. Theoretically, this enthalpy trap strategy could be popularized to all sorts of wireframe cages with free excess ${ }^{41}, 42,43,44$. Yet, as a nature preferred geometry ${ }^{21}$, the icosahedral framework was considered the optimum structure with high stability and sufficient anchoring sites for DNA 
packaging. Meanwhile, stronger rigidity contributed by the two-layer design promoted the stability of the frame structure, the robustness of the packing process, as well as the reconstruction quality of the CryoEM characterization. These advantage was anticipated to keep benefiting future applications to use IDF origami platform as delivery machinery, nanoscaffold for EM based structural analysis, and nanoscaffold for in vivo therapeutics, etc. Moreover, not limited to ssDNA, single-stranded RNA in both circular and linear form could also fit in this packaging strategy. However, double-stranded DNA (dsDNA) as a general form of many viral genomes and plasmids, maintained a fully hybridized formation with high thermal stability and raised challenges for the IDF trapping. A few developed strategies that recruited particular binding agents (e.g. RecA protein ${ }^{45}$, peptide nucleic acid (PNA) ${ }^{46}$, transcription activator-like (TAL) effector proteins ${ }^{47}$, etc.) to tag dsDNA at specific locations offered potential solutions for future In any case, the IDF structure could be expected to load nucleic acid materials of interest as a universal packaging framework.

Besides geometrical similarity endorsed and thermodynamically favored phage ssDNA packaging, the IDF particle showed unforeseen ability in delivering the packed phiX174 genome into the host bacterial cell and inducing phage outbreak. Without the participation of phage spike proteins or cell transformation conditions, this extraordinary infection was ascribed to passive bacterial uptake. Although the mechanism has not been fully discovered, the role of the IDF was speculated as a vehicle which could: 1) protect the packed ssDNA from digestion through bacterial internalization, 2) allow bacterial DNA and RNA polymerase to access the ssDNA to start the replication and transcription process, and 3) provide anchor strands as primers to initiate the synthesis of the anti-sense genome strand. Studies have yet to be done to reveal the IDF internalization pathway in various bacteria cells, which would highly enrich the potential applications of this artificial phage mimetic IDF structure in bacterial engineering.

This highly programmable, high yield, rigid and moderately permeable DNA icosahedral frame has more potential. With modifications on the inner surface, both imaging agents (e.g. fluorescent dyes and nanoparticles, nuclear magnetic resonance materials, radioactive isotopes, etc.) and drug molecules are permitted to load and enrich the inside of the frame with precise numbers and spatial arrangements. Even controllable molecule binding and releasing can be setup and implemented. Moreover, with modifications on the outer surface, this 3D framework could be equipped as an adequate vehicle towards cells by decorating specific recognition agents, such as DNA/RNA aptamers, antibodies, or viral spike proteins. Cell uptake efficiency has been proved to be affected by size, shape, rigidity and vertex curvature of DNA origami structures ${ }^{48}$, which indicated that our virus-like IDF structure has the potential to be an outstanding delivery device in developing the next generation of gene editing or nucleic acid vaccine strategy.

\section{Methods}

\section{Folding and purification of the IDF structures}

The icosahedral DNA origami frame (IDF) structure was designed by using Tiamat. To assemble the IDF structures, 7560 DNA scaffold was mixed with all necessary staple strands 
of $10 \mathrm{nM}$ and total volume of $800 \mathrm{uL}$. The mixed solution was placed in a thermal cycler and underwent a 36 hours annealing process started at $75^{\circ} \mathrm{C}$ for 5 mins and followed with a 65 to $4{ }^{\circ} \mathrm{C}$ programmed temperature ramp at a rate of $-1{ }^{\circ} \mathrm{C} /$ cycle $\times 60$ cycles $(36 \mathrm{~min} / \mathrm{cycle})$.

The assembled structures were purified via a rate-zonal ultra-centrifugation process in glycerol gradients as described previously, concentrated by using Amicon Ultra centrifugal filters (30 $\mathrm{kDa}, 5 \mathrm{~min}$ at $7500 \mathrm{rpm}$ and repeated three times to remove the extra glycerol), and stored frozen at $-20^{\circ} \mathrm{C}$.

\section{Agarose gel electrophoresis (AGE)}

The concentration of purified DNA origami structures were quantified by A260 absorbance using Nanodrop One. Samples (normally $10 \mu \mathrm{L}$ of $5 \mathrm{nM}$ DNA origami) were applied on a1.5\% agarose gel containing GelRed and run electrophoresis at $70 \mathrm{~V}$ for $1-2$ hours at room temperature (running buffer: $0.5 \times \mathrm{TBE}, 10 \mathrm{mM} \mathrm{MgCl}_{2}$ ). Gel images were captured by the CCD equipped on the Amersham Imager 680 (AI680) instrument. Intensities of the interested bands were measured by an open source software ImageJ.

\section{Negatively stained transmission electron microscopy (nsTEM)}

All carbon-coated grids were first glow discharged to increase their hydrophilicity. $5 \mu$ sample solution was placed on the grid surface and incubated for $1 \mathrm{~min}$. Excess solution was adsorbed with filter paper. The grid was then washed by $5 \mu \mathrm{l} 2 \%$ uranium acetate and stained by a second drop for $1 \mathrm{~min}$. After removing the excess staining solution, the grid was left for air-dry. Imaging was performed using a Hitachi-HT7700 microscope operated at $100 \mathrm{kV}$.

\section{Cryogenic temperature transmission electron microscopy (Cryo-TEM)}

Cryo-TEM samples were adsorbed on glow-discharged holey carbon grids (Quantifoil MicroTools), then transferred to and frozen in liquid ethane using FEI Vitrobot. The specimen temperature was maintained below $-170{ }^{\circ} \mathrm{C}$ during data collection. Cryo-EM imaging was performed on a Glacios TEM microscope, operated at $200 \mathrm{kV}$. To collect data for 3D reconstruction, the DNA icosahedron structure was derived from approximately 10,000 manually selected raw particle images. The microscope magnification was $57000 x$, corresponding to $2.5 \AA$ /pixel sampling at the specimen level.

\section{Dynamic light scattering (DLS) measurement}

Hydrodynamic diameter distribution of the $\mathrm{IDF}_{30}$ particles before and after $\Phi_{\mathrm{sSDNA}}$ package were measured by dynamic light scattering using the Malvern Zetasizer ZS instrument, which was equipped with a $633 \mathrm{~nm}$ laser source and a backscattering detector.

\section{The plaque assay}

The purchased $E$. coli (freeze-dried powder) was added to $25 \mathrm{ml}$ LB liquid medium at $37^{\circ} \mathrm{C}$, 200 rpm shaker overnight to resuscitate. The recovered bacteria solution was added to LB liquid medium at ratio $1: 100$ and incubated for about 2 hours at $37^{\circ} \mathrm{C}$ (200rpm shaking), until the $\mathrm{OD}_{600}$ fell into the range of $0.2 \sim 0.8 .10 \mu \mathrm{L}$ of the IDFn- $\Phi$ complex was mixed with $400 \mu \mathrm{L}$ bacteria solution and incubated for $30 \mathrm{~min}$ at $37^{\circ} \mathrm{C}$ (200rpm shaking), then mixed with a premelted $4 \mathrm{ml} 0.5 \%$ agarose medium (cooled down and maintained at $37^{\circ} \mathrm{C}$ ) and poured onto a 
solid LB dish and incubated at $37^{\circ} \mathrm{C}$ for 6 hour. Plaques were manually counted with an error of $\pm 5 \%$.

\section{Acknowledgement}

This work was financially supported by Ministry of Science and Technology of China (2018YFA0902600), and National Natural Science Foundation of China grants (21977069). Bill and Melinda Gates Foundation and the Collaboration for AIDS Vaccine Discovery (CAVD), OPP1115782/INV-002916 (A.B.W.)

\section{Author contributions}

Y.X initiated the project, designed and performed most of the experiments, analyzed the data, and prepared the manuscript. Y.R.Y performed all the cryo-EM data analysis and prepared the manuscript. Q.S. participated to the structure design and assembly. A.B.W. supervised the cryo-EM data analysis and interpreted the data. W.W. supervised the bacteria infection study. Y.Y. initiated the project, designed the DNA origami structure and supervised the study, interpreted the data, and prepared the manuscript. All authors reviewed and approved the manuscript.

\section{Competing financial interests}

Authors declare the following competing financial interests: a provisional patent on the DNAassisted liposome sorting method has been filed.

\section{References}

1. Bos L. 100 years of virology: from vitalism via molecular biology to genetic engineering. Trends Microbiol, 8(2): 82-87. (2000)

2. Altaras NE, Aunins JG, Evans RK, Kamen A, Konz JO, Wolf JJ. Production and formulation of adenovirus vectors. Adv Biochem Eng Biotechnol, 99: 193-260. (2005)

3. Smith GP, Petrenko VA. Phage Display. Chem Rev, 97(2): 391-410. (1997)

4. Finlay WJ, Bloom L, Cunningham O. Phage display: a powerful technology for the generation of high specificity affinity reagents from alternative immune sources. Methods Mol Biol, 681: 87-101. (2011)

5. Summers WC. Bacteriophage therapy. Annu Rev Microbiol, 55: 437-451. (2001)

6. Yang $\mathrm{Y}$, Zhang R, Fan C. Shaping Functional Materials with DNA Frameworks. Trends in Chemistry, 2(2): 137-147. (2020)

7. Seeman NC, Sleiman HF. DNA nanotechnology. Nat Rev Mater, 3(1). (2018)

8. Hu Y, Niemeyer CM. From DNA Nanotechnology to Material Systems Engineering. Adv Mater, 31(26): e1806294. (2019) 
9. Perrault SD, Shih WM. Virus-inspired membrane encapsulation of DNA nanostructures to achieve in vivo stability. ACS Nano, 8(5): 5132-5140. (2014)

10. Garmann RF, Sportsman R, Beren C, Manoharan VN, Knobler CM, Gelbart WM. A Simple RNA-DNA Scaffold Templates the Assembly of Monofunctional Virus-Like Particles. J Am Chem Soc, 137(24): 7584-7587. (2015)

11. Sigl C, Willner EM, Engelen W, Kretzmann JA, Sachenbacher K, Liedl A, Kolbe F, Wilsch F, Aghvami SA, Protzer U, Hagan MF, Fraden S, Dietz H. Programmable icosahedral shell system for virus trapping. Nat Mater, 20(9): 1281-1289. (2021)

12. Mikkila J, Eskelinen AP, Niemela EH, Linko V, Frilander MJ, Torma P, Kostiainen MA. Virusencapsulated DNA origami nanostructures for cellular delivery. Nano Lett, 14(4): 2196-2200. (2014)

13. Veneziano R, Moyer TJ, Stone MB, Wamhoff EC, Read BJ, Mukherjee S, Shepherd TR, Das $\mathrm{J}$, Schief WR, Irvine DJ, Bathe M. Role of nanoscale antigen organization on B-cell activation probed using DNA origami. Nat Nanotechnol, 15(8): 716-723. (2020)

14. Zhao Z, Zhang M, Hogle JM, Shih WM, Wagner G, Nasr ML. DNA-Corralled Nanodiscs for the Structural and Functional Characterization of Membrane Proteins and Viral Entry. J Am Chem Soc, 140(34): 10639-10643. (2018)

15. Zhou K, Ke Y, Wang Q. Selective in Situ Assembly of Viral Protein onto DNA Origami. J Am Chem Soc, 140(26): 8074-8077. (2018)

16. Denhardt DT, Model P. The Single-Stranded DNA Phages. CRC Critical Reviews in Microbiology, 4(2): 161-223. (1975)

17. Fujisawa $\mathrm{H}$, Hayashi $\mathrm{M}$. Viral DNA-synthesizing intermediate complex isolated during assembly of bacteriophage phi X174. J Virol, 19(2): 409-415. (1976)

18. Hafenstein S, Fane BA. phi X174 genome-capsid interactions influence the biophysical properties of the virion: evidence for a scaffolding-like function for the genome during the final stages of morphogenesis. J Virol, 76(11): 5350-5356. (2002)

19. McKenna R, llag LL, Rossmann MG. Analysis of the single-stranded DNA bacteriophage phi X174, refined at a resolution of 3.0 A. J Mol Biol, 237(5): 517-543. (1994)

20. McKenna R, Xia D, Willingmann P, llag LL, Krishnaswamy S, Rossmann MG, Olson NH, Baker TS, Incardona NL. Atomic structure of single-stranded DNA bacteriophage phi X174 and its functional implications. Nature, 355(6356): 137-143. (1992) 
21. Dion MB, Oechslin F, Moineau S. Phage diversity, genomics and phylogeny. Nat Rev Microbiol, 18(3): 125-138. (2020)

22. Lin C, Perrault SD, Kwak M, Graf F, Shih WM. Purification of DNA-origami nanostructures by rate-zonal centrifugation. Nucleic Acids Res, 41(2): e40. (2013)

23. Banerjee A, Bhatia D, Saminathan A, Chakraborty S, Kar S, Krishnan Y. Controlled release of encapsulated cargo from a DNA icosahedron using a chemical trigger. Angew Chem Int Ed Engl, 52(27): 6854-6857. (2013)

24. Bhatia D, Mehtab S, Krishnan R, Indi SS, Basu A, Krishnan Y. Icosahedral DNA nanocapsules by modular assembly. Angew Chem Int Ed Engl, 48(23): 4134-4137. (2009)

25. Knappe GA, Wamhoff EC, Read BJ, Irvine DJ, Bathe M. In Situ Covalent Functionalization of DNA Origami Virus-like Particles. ACS Nano, 15(9): 14316-14322. (2021)

26. Zhang F, Jiang S, Wu S, Li Y, Mao C, Liu Y, Yan H. Complex wireframe DNA origami nanostructures with multi-arm junction vertices. Nat Nanotechnol, 10(9): 779-784. (2015)

27. Tinland B, Pluen A, Sturm J, Weill G. Persistence Length of Single-Stranded DNA. Macromolecules, 30(19): 5763-5765. (1997)

28. Rivetti C, Walker C, Bustamante C. Polymer chain statistics and conformational analysis of DNA molecules with bends or sections of different flexibility. J Mol Biol, 280(1): 41-59. (1998)

29. Rothemund PW. Folding DNA to create nanoscale shapes and patterns. Nature, 440(7082): 297-302. (2006)

30. Sun L, Young LN, Zhang X, Boudko SP, Fokine A, Zbornik E, Roznowski AP, Molineux IJ, Rossmann MG, Fane BA. Icosahedral bacteriophage PhiX174 forms a tail for DNA transport during infection. Nature, 505(7483): 432-435. (2014)

31. Anderson B, Rashid MH, Carter C, Pasternack G, Rajanna C, Revazishvili T, Dean T, Senecal A, Sulakvelidze A. Enumeration of bacteriophage particles: Comparative analysis of the traditional plaque assay and real-time QPCR- and nanosight-based assays. Bacteriophage, 1(2): 86-93. (2011)

32. Slattery SD, Valentine CR. Development of a microplate assay for the detection of single plaque-forming units of bacteriophage PhiX174 in crude lysates. Environ Mol Mutagen, 41(2): 121-125. (2003)

33. McCormick W, Mermel LA. The basic reproductive number and particle-to-plaque ratio: comparison of these two parameters of viral infectivity. Virol J, 18(1): 92. (2021) 
34. Mercenier A, Chassy BM. Strategies for the development of bacterial transformation systems. Biochimie, 70(4): 503-517. (1988)

35. Ponnuswamy N, Bastings MMC, Nathwani B, Ryu JH, Chou LYT, Vinther M, Li WA, Anastassacos FM, Mooney DJ, Shih WM. Oligolysine-based coating protects DNA nanostructures from low-salt denaturation and nuclease degradation. Nat Commun, 8: 15654. (2017)

36. Mela I, Vallejo-Ramirez PP, Makarchuk S, Christie G, Bailey D, Henderson RM, Sugiyama H, Endo M, Kaminski CF. DNA Nanostructures for Targeted Antimicrobial Delivery. Angew Chem Int Ed Engl, 59(31): 12698-12702. (2020)

37. Chen I, Dubnau D. DNA uptake during bacterial transformation. Nat Rev Microbiol, 2(3): 241-249. (2004)

38. Dubnau D, Blokesch M. Mechanisms of DNA Uptake by Naturally Competent Bacteria. Annu Rev Genet, 53: 217-237. (2019)

39. Mell JC, Redfield RJ. Natural competence and the evolution of DNA uptake specificity. $J$ Bacteriol, 196(8): 1471-1483. (2014)

40. Eisenberg S, Denhardt DT. Structure of nascent phiX174 replicative form: evidence for discontinuous DNA replication. Proc Natl Acad Sci U S A, 71(3): 984-988. (1974)

41. Benson E, Mohammed A, Gardell J, Masich S, Czeizler E, Orponen P, Hogberg B. DNA rendering of polyhedral meshes at the nanoscale. Nature, 523(7561): 441-444. (2015)

42. Veneziano R, Ratanalert S, Zhang K, Zhang F, Yan H, Chiu W, Bathe M. Designer nanoscale DNA assemblies programmed from the top down. Science, 352(6293): 1534. (2016)

43. Han D, Pal S, Yang Y, Jiang S, Nangreave J, Liu Y, Yan H. DNA gridiron nanostructures based on four-arm junctions. Science, 339(6126): 1412-1415. (2013)

44. Zhang Z, Yang Y, Pincet F, Llaguno MC, Lin CX. Placing and shaping liposomes with reconfigurable DNA nanocages. Nat Chem, 9(7): 653-659. (2017)

45. Sharma R, Davies AG, Walti C. RecA protein mediated nano-scale patterning of DNA scaffolds. J Nanosci Nanotechnol, 11(12): 10629-10632. (2011)

46. Muller P, Rossler J, Schwarz-Finsterle J, Schmitt E, Hausmann M. PNA-COMBO-FISH: From combinatorial probe design in silico to vitality compatible, specific labelling of gene targets in cell nuclei. Exp Cell Res, 345(1): 51-59. (2016) 
47. Praetorius F, Dietz H. Self-assembly of genetically encoded DNA-protein hybrid nanoscale shapes. Science, 355(6331). (2017)

48. Hu Q, Wang S, Wang L, Gu H, Fan C. DNA Nanostructure-Based Systems for Intelligent 


\section{Supplementary Information}

\section{An infectious virus-like particle built on a programmable icosahedral DNA framework}

Yunyun Xu, Yuhe R. Yang, Qian Shi, Andrew B. Ward, Wei Wang, Yang Yang

\section{Contents}

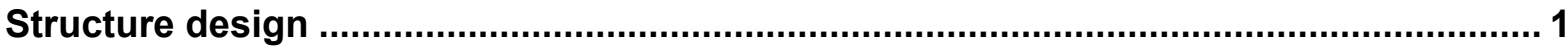

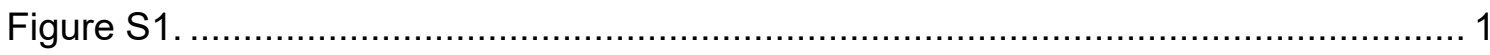

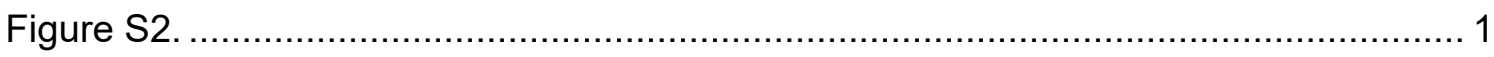

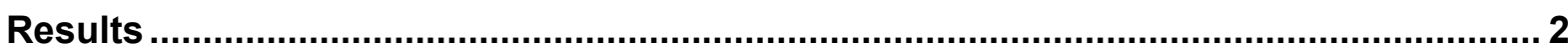

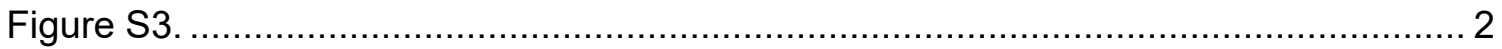

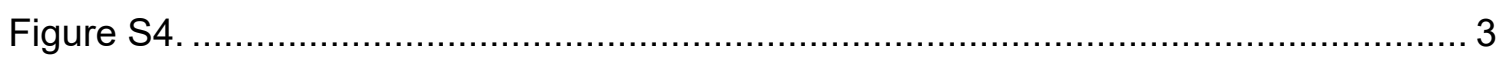

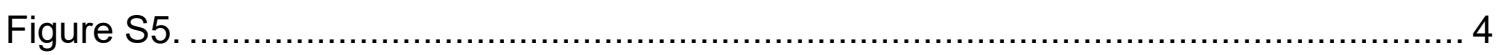

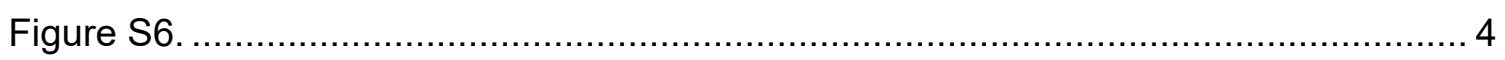

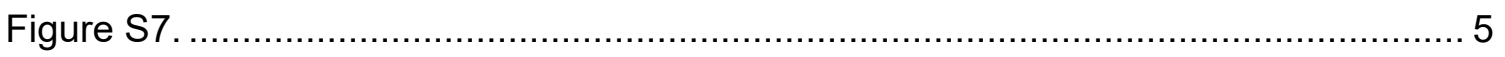

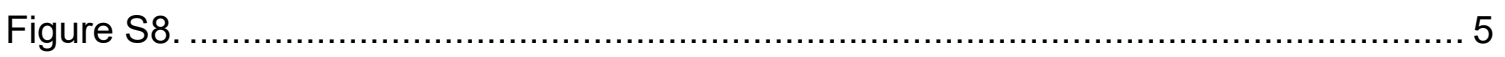

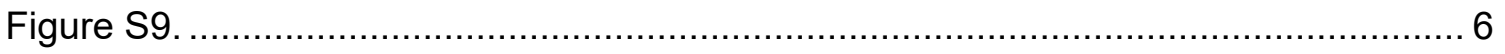

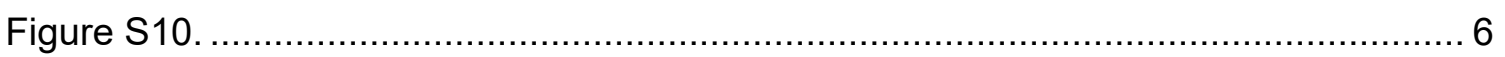

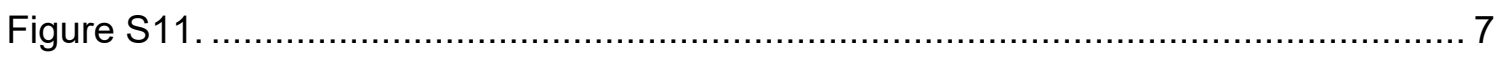

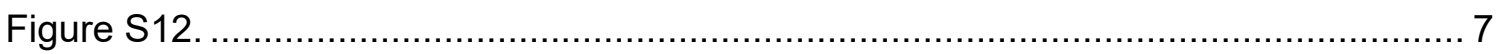

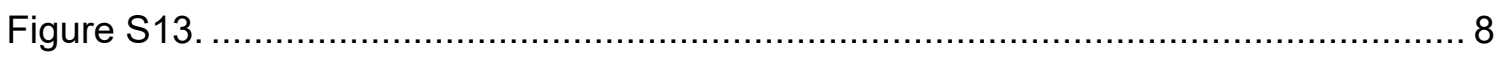

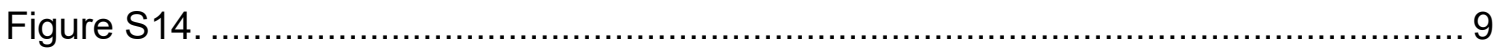

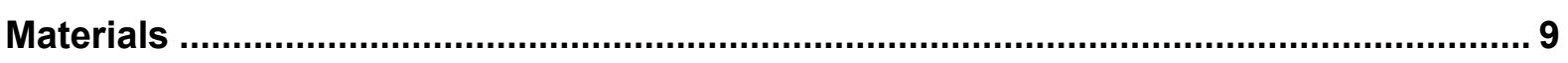

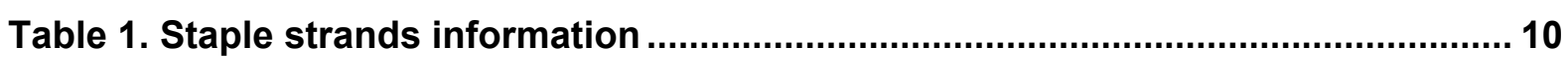




\section{Structure design}

Blue print of the unfolded IDF - Top view

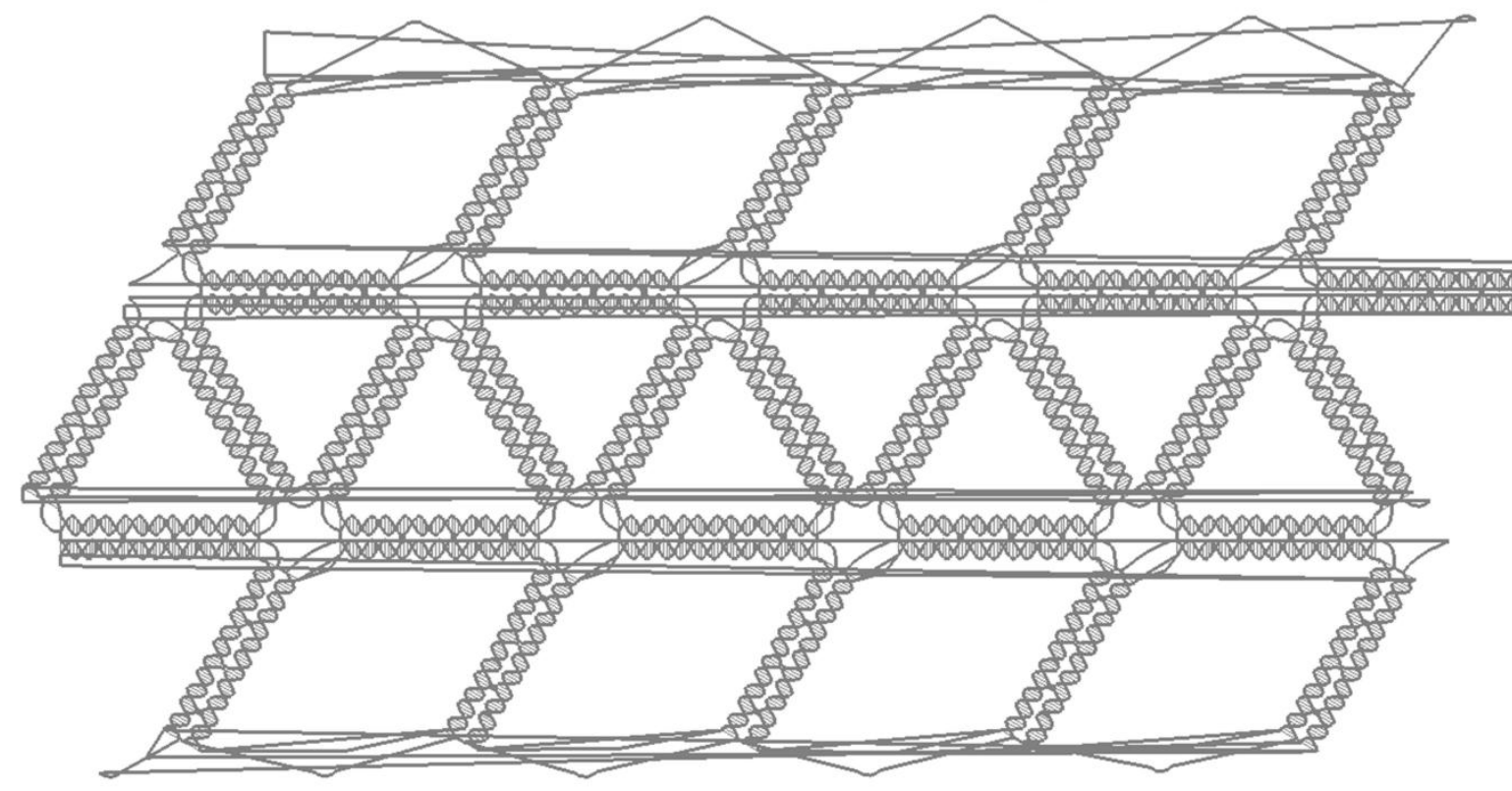

Blue print of the unfolded IDF - Side view

Addition layer

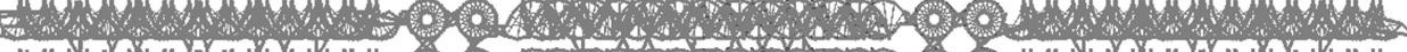

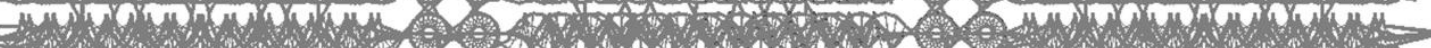
Foundation layer

Figure S1. Blue print of the unfolded icosahedral DNA framework designed by Tiamat.

Addition layer formed by a $126 \mathrm{nt}$ loop

Scaffold routing of one edge of the IDF Flat view
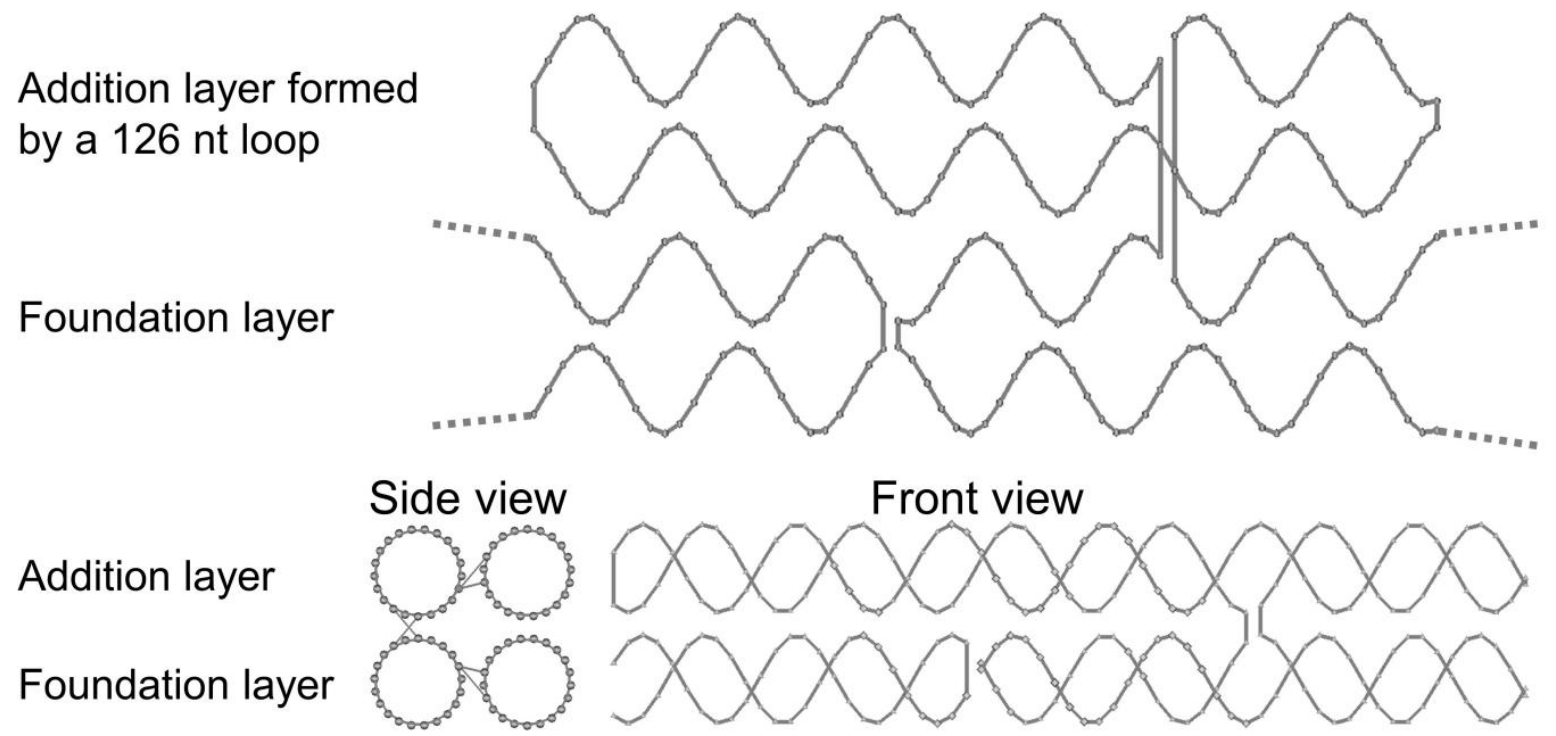

Figure S2. Details of the scaffold routing design on one edge. Top: the four helixes of the edge were arranged in an un-overlapped flat view to show the relationship between the addition layer and the foundation layer. Bottom: the side view and front view of the exampled edge at overlapped state. Note that all the staple strands were removed from this scheme to better exhibit the scaffold routing. 


\section{Results}

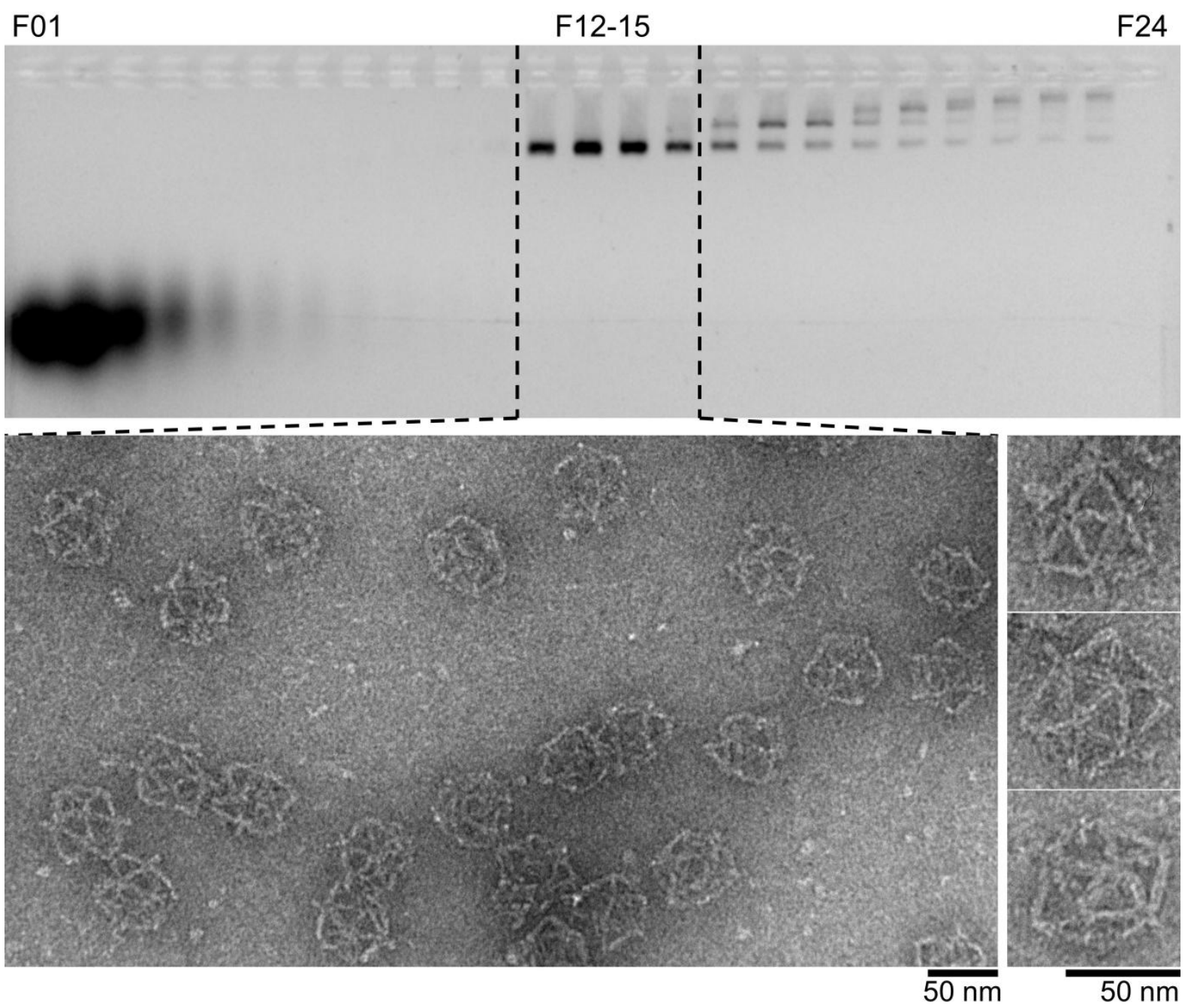

Figure S3. IDF structure purification and characterization. Top: representative agarose gel image of the ultracentrifugation products of an IDF 0 sample. Fractions 1-24 were collected from the top to the bottom of the glycerol gradient. F1-7 contained most of the extra staple strands, F12-15 contained only well assembled monomer IDF (combined for future use), and later fractions contained byproducts such as higher order structures and aggregates. Bottom: nsTEM images of the purified IDF 0 structure recovered from F12-15. 


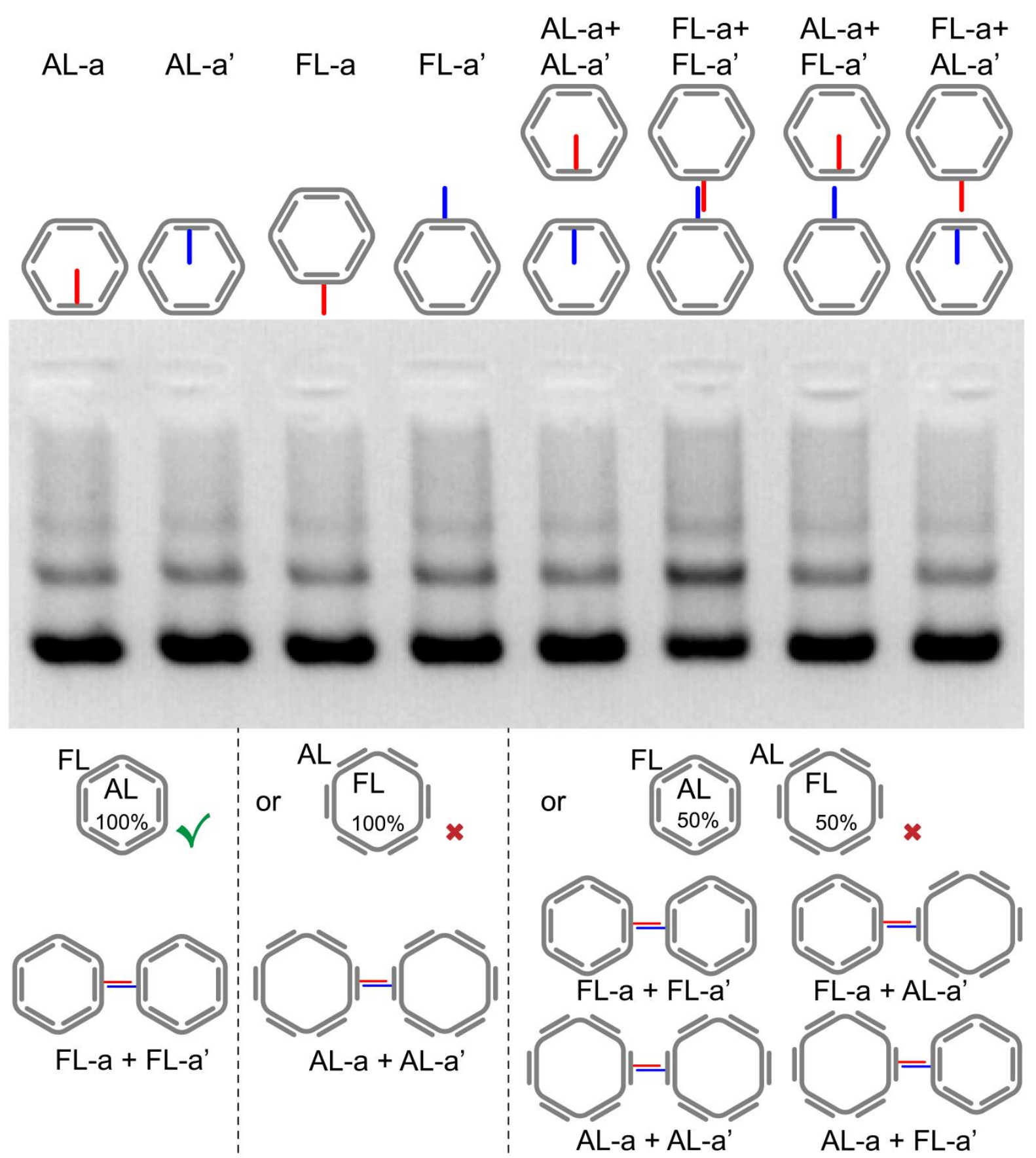

Figure S4. Verification of the structure topology. As shown in the top panel, four types of IDF variants with a or a' handle sequence protruding from the addition layer or the foundation layer were assembled and purified. The monomers were mixed with each other at 1:1 ratio followed with a one hour incubation at $37^{\circ} \mathrm{C}$. All of the eight samples were applied to agarose gel electrophoresis, and only sample FL-a +FL-a' yielded an increased dimer band intensity. Bottom panel listed all the possible topological preferences with their achievable dimer species. AGE image indicated that the IDF structure folded its addition layer towards the inside while the foundation layer facing outside of the icosahedron. 

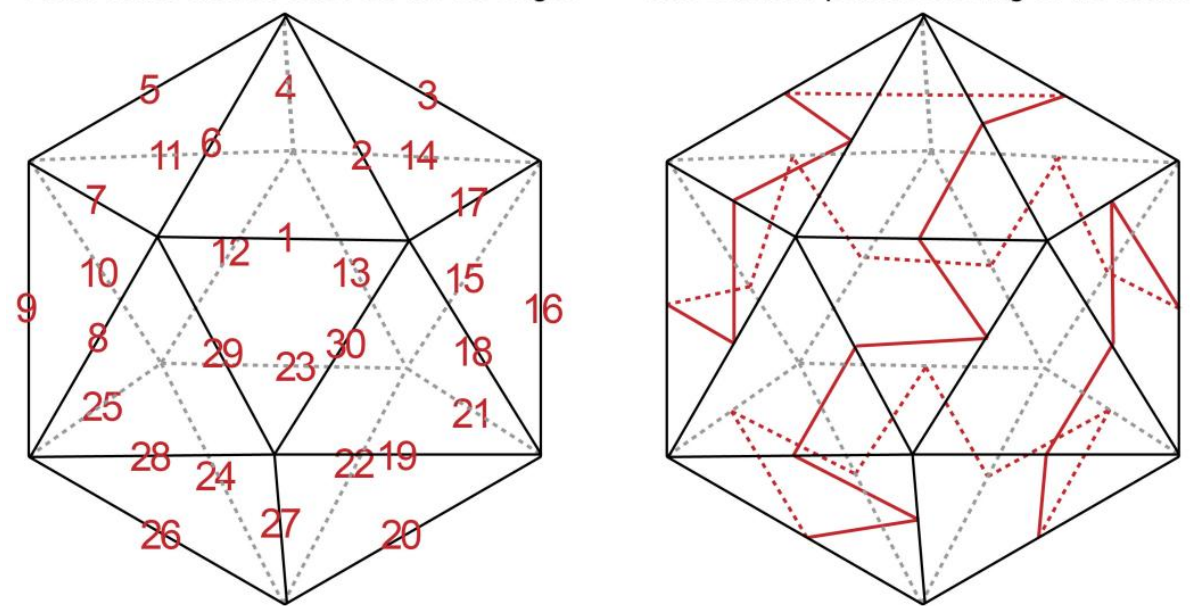

Figure S5. Arrangement of the anchor sites. The 30 edges of the IDF structure were assigned with numbers (left) following the Eulerian order which assured the shortest length between adjacent numbers (right). 30 anchor strands targeting the $\Phi_{\text {SSDNA }}$ were protruded from the staples on the addition layer of edges following the defined order.

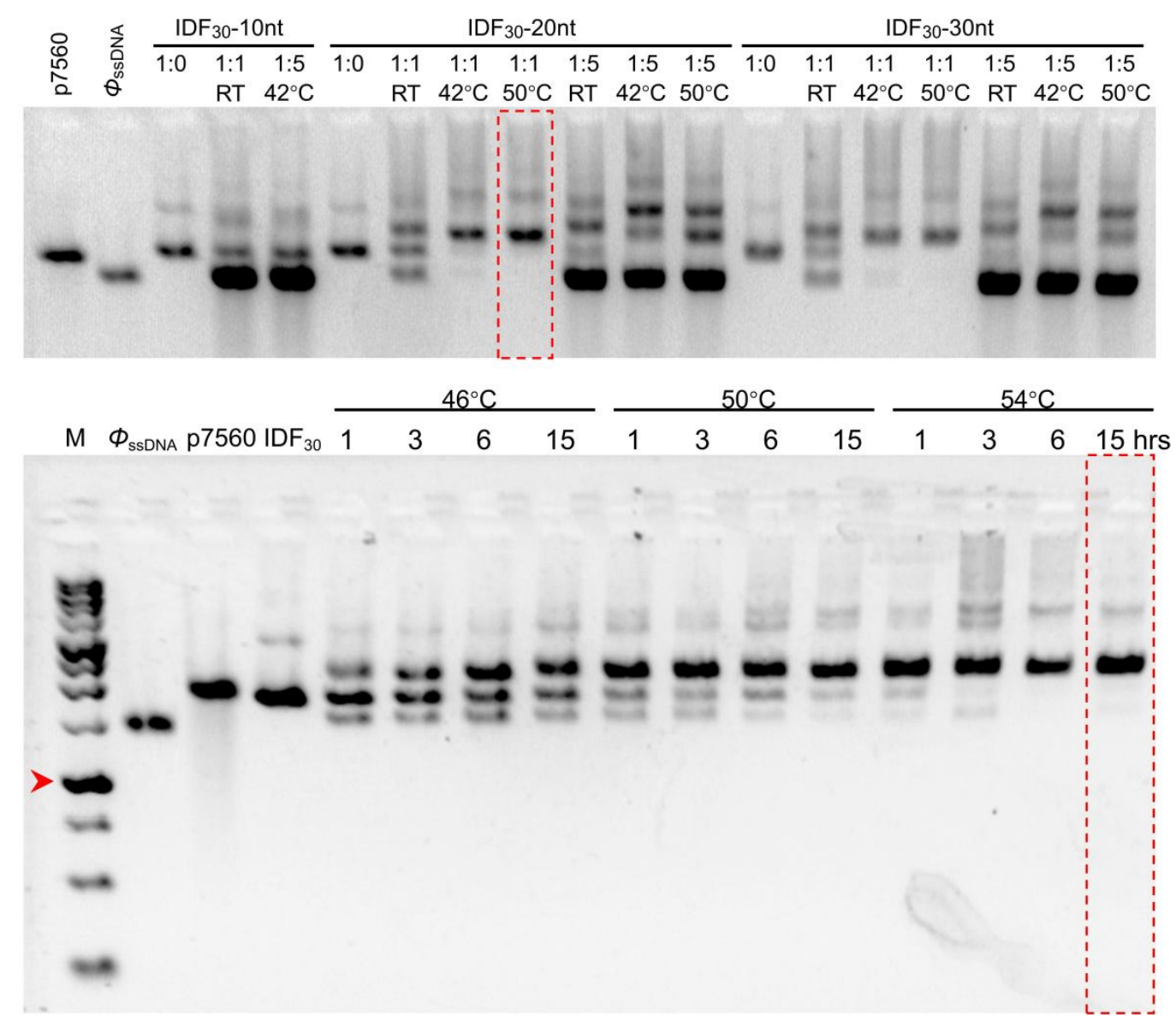

Figure S6. Optimization of the $\Phi_{\text {SSDNA }}$ packaging conditions with AGE analysis. Top: comparison of the packaging efficiency with varied anchor strand lengths, IDF 30 to $\Phi_{\text {SsDNA }}$ ratios, and temperatures for an overnight $(>18 \mathrm{hrs})$ thermostatic incubation. Bottom: with the 20nt anchor and the 1:1 ratio fixed, the incubation temperature and lasting time were further examined. Dashed red boxes showed the results at the best conditions, in which both the $\mathrm{IDF}_{30}$ and the $\Phi_{\text {SSDNA }}$ bands vanished while a single product band with slower mobility emerged. Red arrow indicates the 1000 bp DNA marker band. 

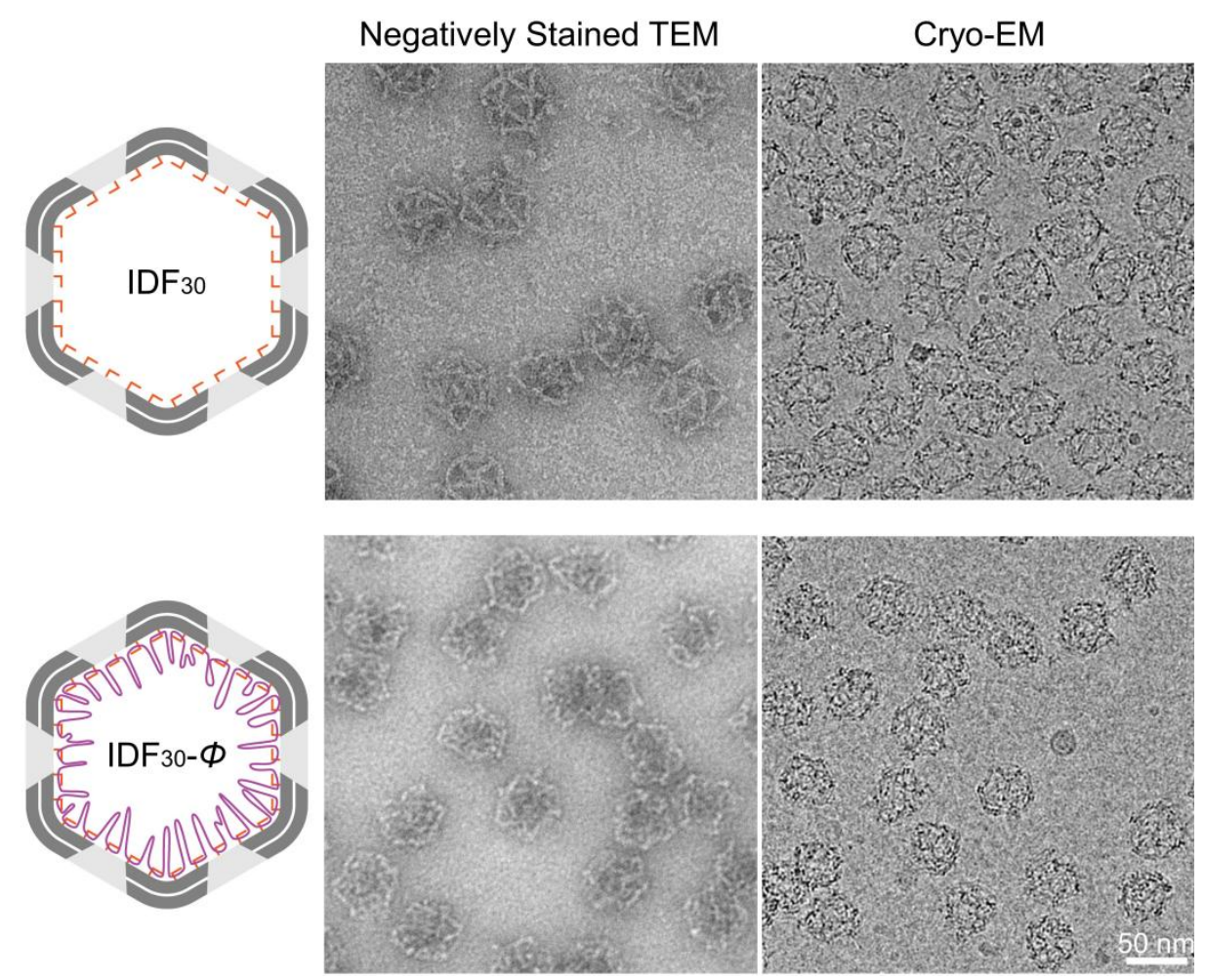

Figure S7. Representative nsTEM and CryoEM images of both IDF 30 and IDF ${ }_{30} \Phi$.

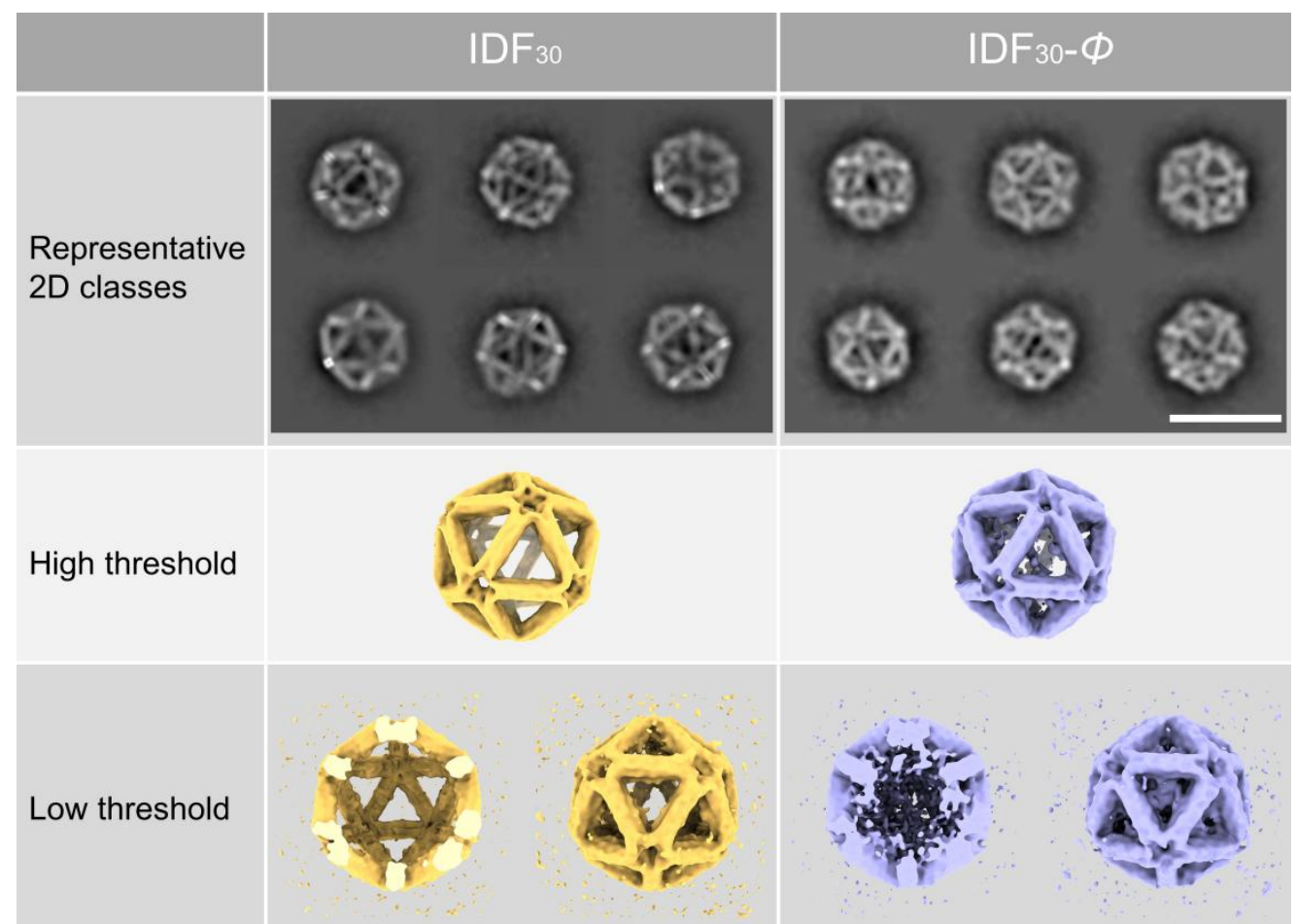

Figure S8. CryoEM image processing and analysis. Single particle analysis was applied to the data acquired from cryoEM imaging for both $I^{2} F_{30}$ and IDF ${ }_{30}-\Phi$ samples. Representative images of the 2D classes and the 3D reconstructed structures at two different density threshold levels were exhibited. Scale bar: $50 \mathrm{~nm}$. 


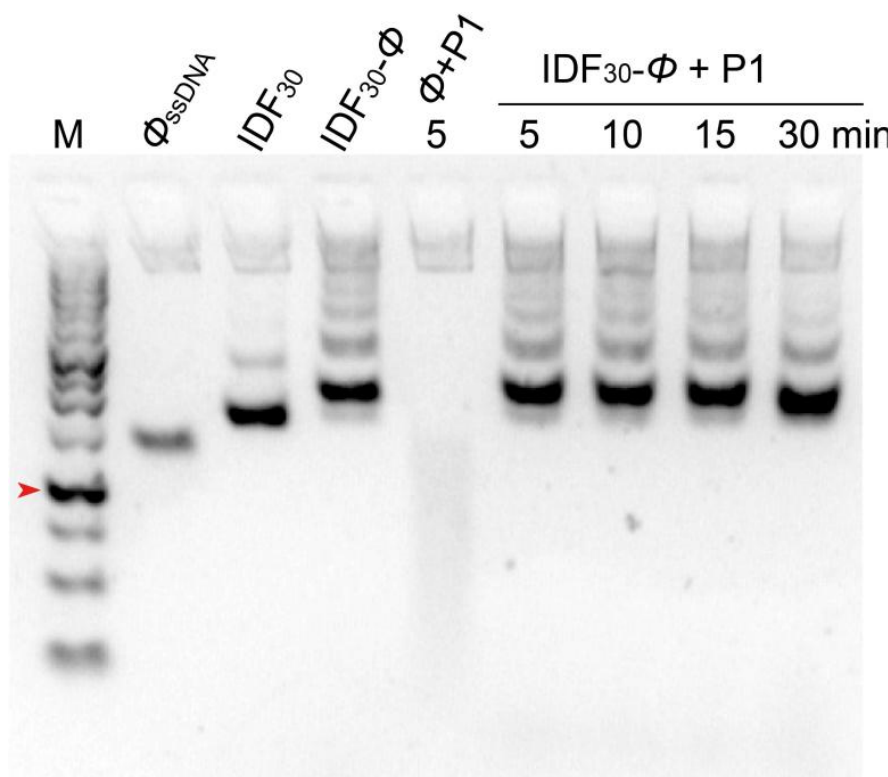

Figure S9. AGE analysis of the P1 nuclease induced ssDNA digestion for both naked and packed phiX174 genome (red arrow indicates the 1000 bp DNA marker band).

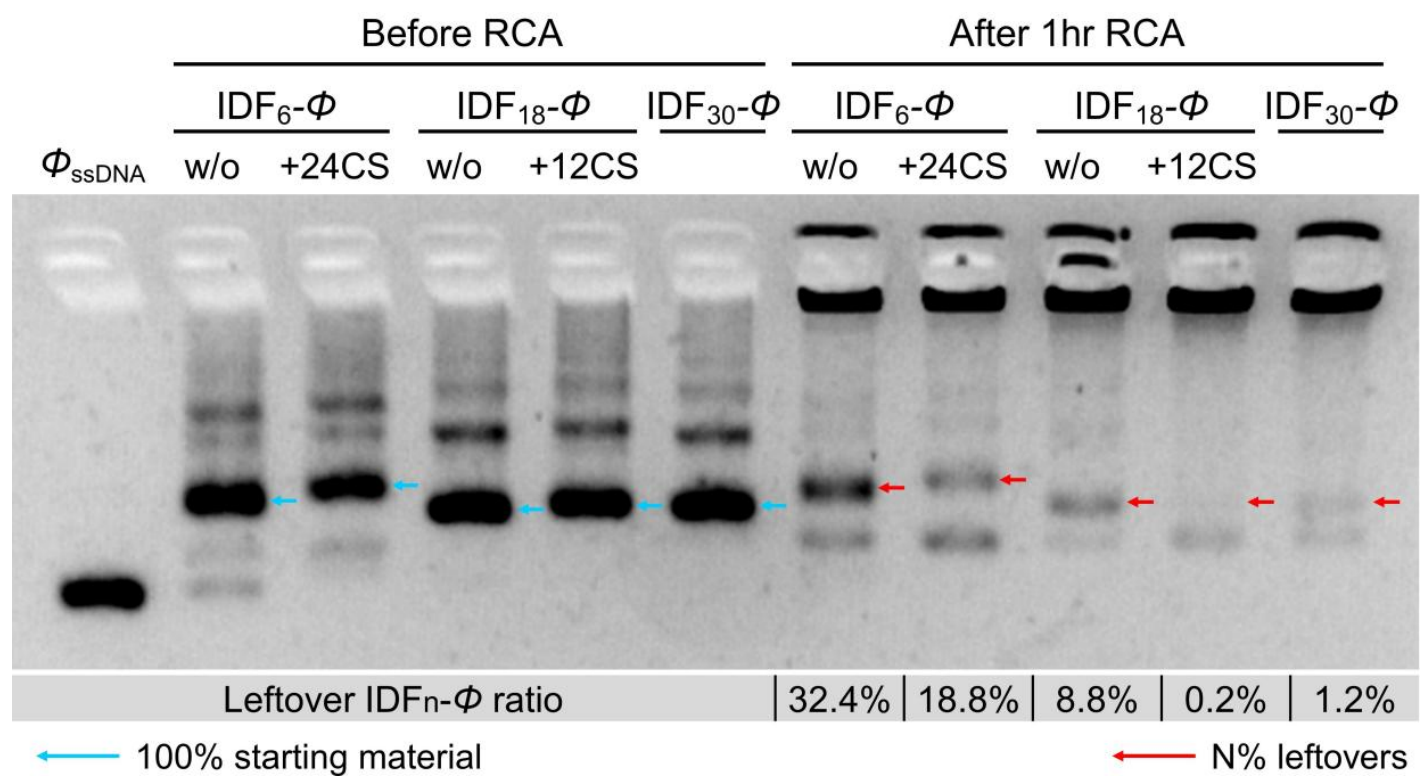

Figure S10. Anchor number dependent RCA reaction efficiency analyzed by AGE. The $\Phi_{\text {ssDNA }}$ was packed by $\operatorname{IDF}_{n}(n=6,18$ or 30$)$ variants with or without the compensatory strands. The phi29 polymerase was introduced to these samples and performed the RCA reaction for 1 hour. Considering that the RCA products would gain huge molecular weight or form aggregates, the remained sharp bands with unchanged mobility (pointed by the red arrows) indicated the un-reacted complexes (a.k.a leftovers). The leftover IDF $F_{n} \Phi$ ratio could then be calculated by comparing the intensity of the leftover bands and the original bands (packed products without RCA reaction). 


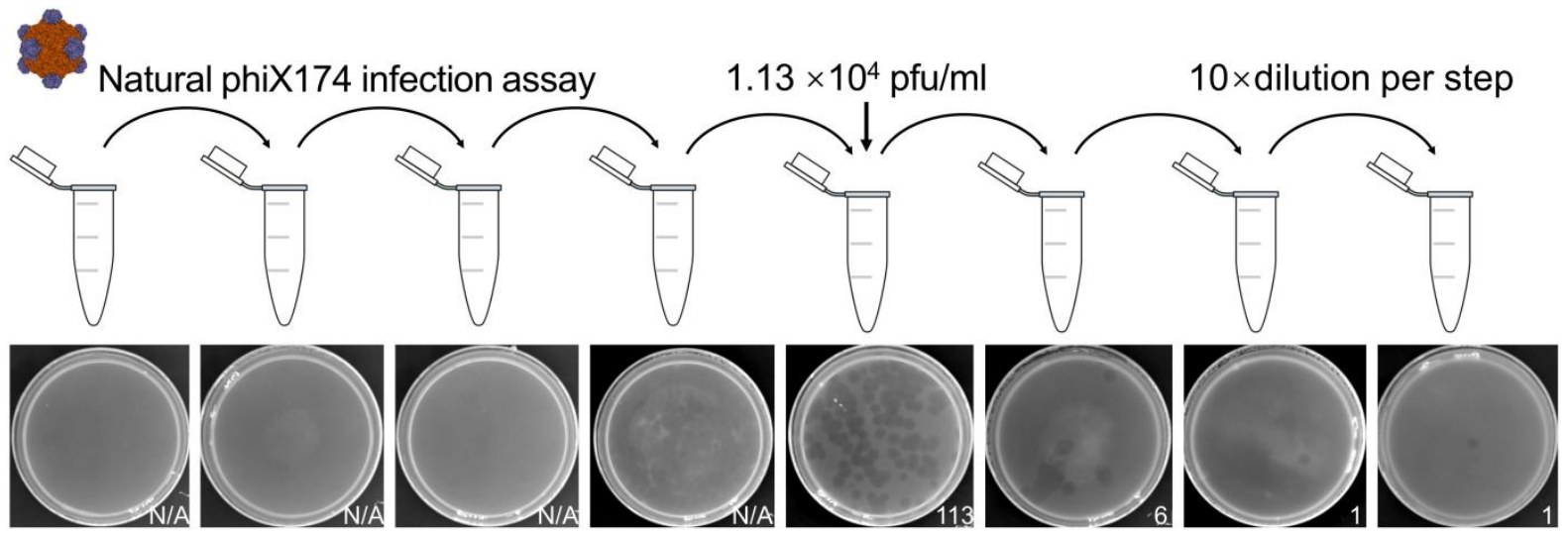

Figure S11. Natural phiX174 infection assay. As a positive control, the original solution of the phiX174 bacteriophage was applied to a sequential dilution (10× per step). $10 \mu \mathrm{L}$ of each diluted sample was mixed with $400 \mu \mathrm{L}$ bacteria solution and incubated for $30 \mathrm{~min}$ at $37^{\circ} \mathrm{C}$ (200rpm shaking), then mixed with a pre-melted $4 \mathrm{ml} 0.5 \%$ agarose medium (cooled down and maintained at $37^{\circ} \mathrm{C}$ ) and poured onto a solid LB dish and incubated at $37^{\circ} \mathrm{C}$ for 2 hour.

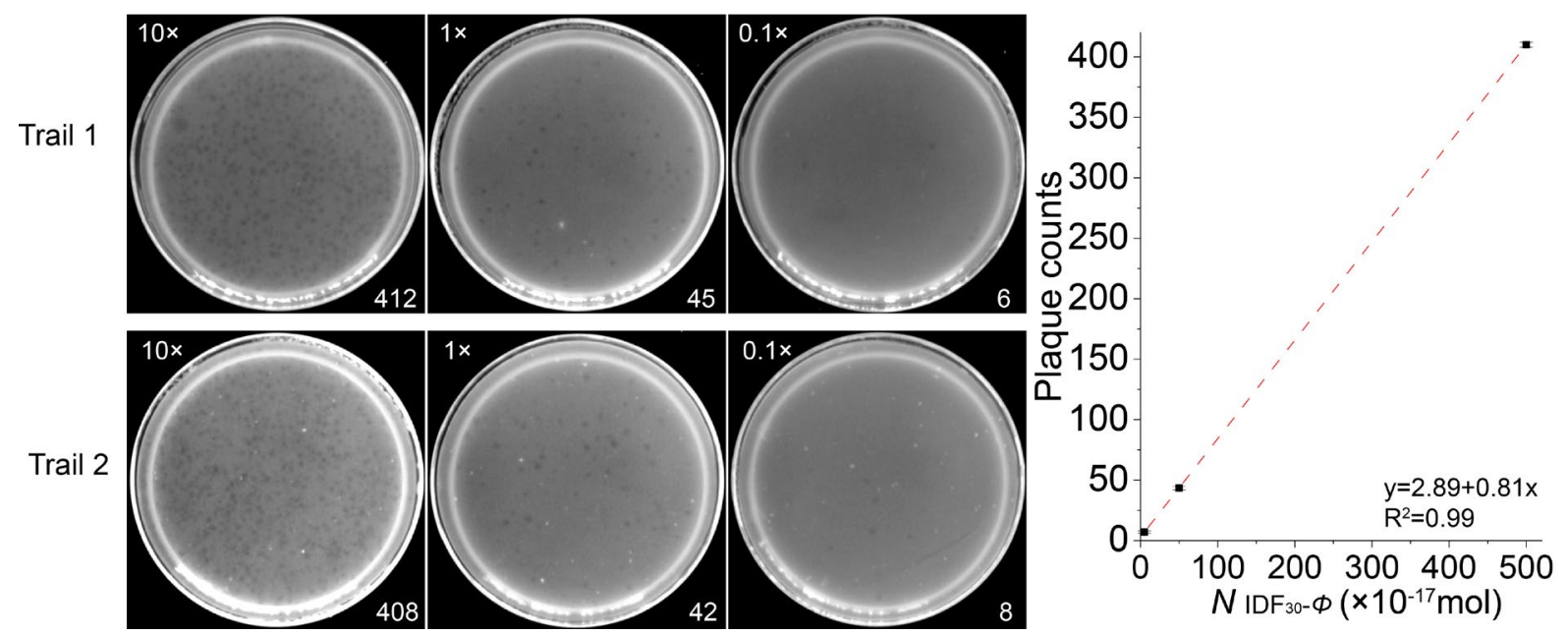

Figure S12. Concentration dependent $\mathrm{IDF}_{30} \Phi$ induced infection. Left: in two independent trails, 10,1 and $0.1 \mu \mathrm{L}$ of $24 \mathrm{nM}^{\mathrm{IDF}} \mathrm{I}_{30} \Phi$ were mixed with the $400 \mu \mathrm{L}$ E. coli solution and performed the plaque assay as described in the method section in main text. Right: the counted plaque number followed a perfect linear relationship with the added IDF ${ }_{30}-\Phi$ amount. From the linear equation, a particle $\left(\operatorname{IDF}_{30^{-}} \Phi\right)$ to pfu ratio of $7.5 \times 10^{6}$ could be derived. 


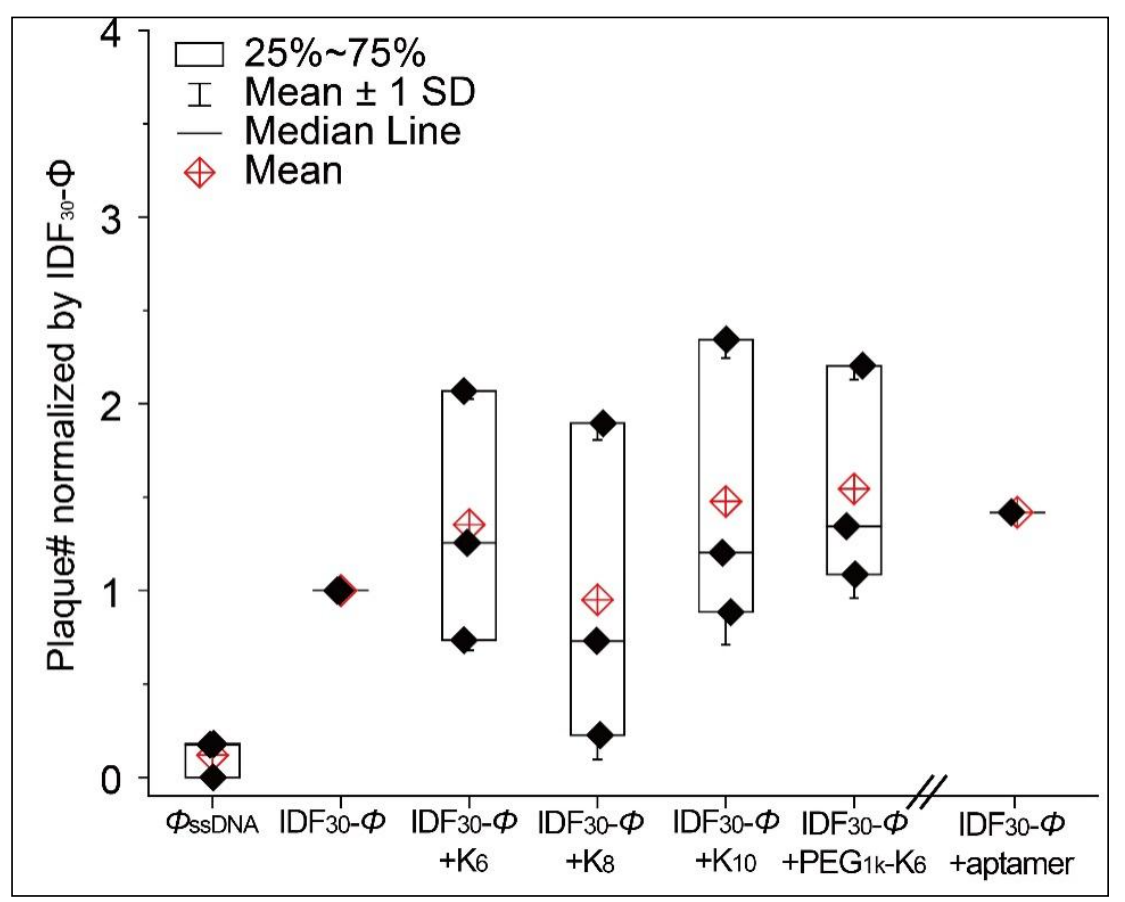

Figure S13. Infection efficiency analysis of the modified IDF ${ }_{30}-\Phi$ particles. Three independent trials of $K_{n}(n=6,8$ or 10$)$ and $P E G_{1 k}-K_{6}$ coated $I D F_{30}-\Phi$ were compared with the unmodified $I^{I D F_{30}} \Phi$ and unpacked $\Phi_{\text {sSDNA. }}$. Extremely large batch to batch difference were observed, which might attribute to peptide (oligolysine) DNA disassociation at the bacterial culturing environment or peptide involved bacterial nutrition. Although $\mathrm{K}_{10}$ and $P E \mathrm{G}_{1 \mathrm{k}}-\mathrm{K}_{6}$ group yielded in average $50 \%$ more plaque formation compare to the unmodified IDF ${ }_{30}-\Phi$, it was hard to conclude that the surface charge or PEG modification played a key role in the $I D F_{30}-\Phi$ internalization. Meanwhile, a single test of the 30 aptamers modified $I^{2} F_{30}-\Phi$ yielded a comparable number of plaques, which was not attractive enough to pursue further. 


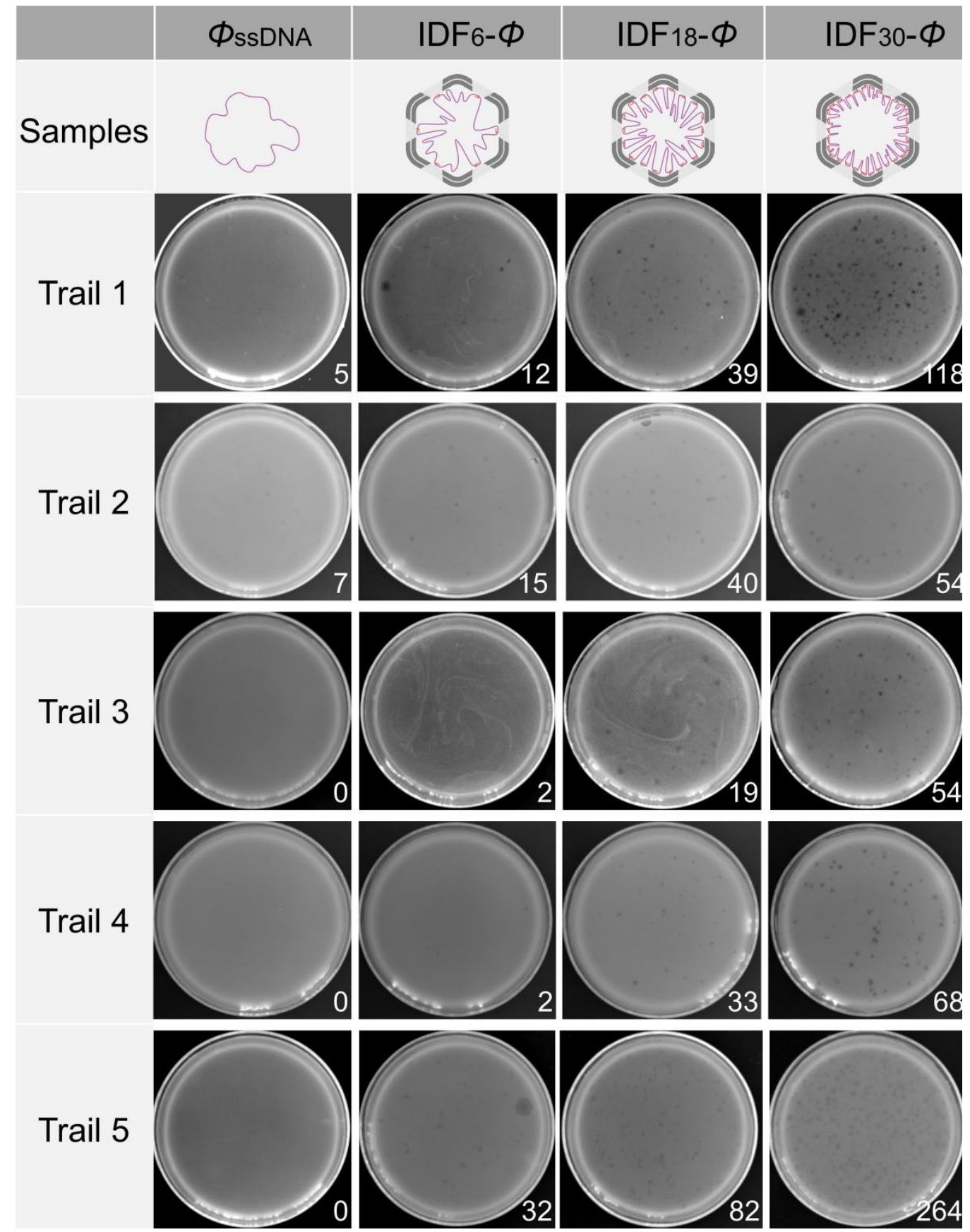

Figure S14. Five independent trials of $\Phi_{\mathrm{sSDNA}}$ and $\mathrm{IDF}_{\mathrm{n}}-\Phi(\mathrm{n}=6,18$ and 30$)$ induced infection. Although batch to batch differences were obvious, the evidence that $\Phi_{\text {ssDNA }}$ could barely yield plaque and the trend of anchor number dependent infection efficiency were recognizable. Box analysis of the normalized data were shown in Figure $5 \mathrm{~b}$ in the main text.

\section{Materials}

Scaffold DNA p7560 was purchased from Integrated DNA Technologies, Pte. Ltd. (USA). Single-stranded phiX174 genome was purchased from Gene Company Limited (Shanghai). DNA oligonucleotides (staple strands) were synthesized by Sangon Biotech (Shanghai) Co., Ltd. Oligolysines were synthesized by China Peptides Co., Ltd. (Shanghai). Regular chemicals and bacterial culturing materials were purchased from Corning Inc. (USA).

All of the staples participated to this study were listed in Table 1, as shown below. 
Table 1. Staple strands information

\begin{tabular}{|c|c|c|}
\hline Name & Sequence & Length \\
\hline ico-vertex-FL-001 & AGACATTTTTGTCAAATCACCGTACCCCGGTTTTTTTGATAATCAGAAA & 49 \\
\hline ico-vertex-FL-002 & AATTCTTTTTGCGTCTGGCCTAGTATCGGCCTTTTTTCAGGAAGATCGC & 49 \\
\hline ico-vertexF-L-003 & TTTTGTTTTTTTAAAATTCGCA & 22 \\
\hline ico-vertex-FL-004 & AATTATTTTTACCGTTGTAGCGATAGGGTTGATTTTTGTGTTG & 43 \\
\hline ico-vertex-FL-005 & TAGGGTTTTTCGCTGGCAAGTGGAACGGTACGTTTTTCCAGAATCCTGA & 49 \\
\hline ico-vertex-FL-006 & TTCCACCCCCGATTTATTTTTGAGCTTGACGGG & 33 \\
\hline ico-vertex-FL-007 & ATTGCTTTTTTCCTTTTGATATAGATACATTTTTTTTCGCAAATGGTCA & 49 \\
\hline ico-vertex-FL-008 & CCAATTTTTTACTGCGGAATCATCGCGTTTTATTTTTATTCGAGCTTCA & 49 \\
\hline ico-vertex-FL-009 & TTCTATTTTTCTAATAGTAGTA & 22 \\
\hline ico-vertex-FL-010 & AGGCTTTTTTTTTTGCAAAAGACCTCATATATTTTTTTTTAAAT & 43 \\
\hline ico-vertex-FL-011 & AAGTTTTTTTTGAGTAACATTAGGAATTACGATTTTTGGCATAGTAAGA & 49 \\
\hline ico-vertex-FL-012 & GCAATGCCAGGGTTTTTTTTTCCCAGTCACGAC & 33 \\
\hline ico-vertex-FL-013 & TAGACTTTTTTTTACAAACAACGCCCTGGAGTTTTTTGACTCTATGATA & 49 \\
\hline ico-vertex-FL-014 & ATAAATTTTTACAGAGGTGAGCTAAAATATCTTTTTTTTAGGAGCACTA & 49 \\
\hline ico-vertex-FL-015 & GGCCTTTTTTTGAATCGGCTGA & 22 \\
\hline ico-vertex-FL-016 & ATGCGTTTTTCGAACTGATAGTTATCCGCTCATTTTTCAATTC & 43 \\
\hline ico-vertex-FL-017 & TCAAATTTTTCTATCGGCCTTCAGAGATAGAATTTTTCCCTTCTGACCT & 49 \\
\hline ico-vertex-FL-018 & CACACGCGTATTGGGCTTTTTGCCAGGGTGGTT & 33 \\
\hline ico-vertex-FL-019 & TCACCTTTTTGTACTCAGGAGCAGCCCTCATATTTTTGTTAGCGTAACG & 49 \\
\hline ico-vertex-FL-020 & GGGTTTTTTTTTTGCTCAGTACC & 22 \\
\hline ico-vertex-FL-021 & TTTGCTTTTTTAAACAACTTTGATACCGATAGTTTTTTTGCGCCGACAA & 49 \\
\hline ico-vertex-FL-022 & CATGAGAAGTTTCCATTTTTTTAAACGGGTAAA & 33 \\
\hline ico-vertex-FL-023 & AATAATTTTTATCCTCATTAAAACCTATTATTTTTTTCTGAAA & 43 \\
\hline ico-vertex-FL-024 & ACTAATTTTTAACACTCATCTAAAGAGGACAGTTTTTATGAACGGTGTA & 49 \\
\hline ico-vertex-FL-025 & CCGCCTTTTTGCCAGCATTGATCAACTTTAATTTTTTCATTGTGAATTA & 49 \\
\hline ico-vertex-FL-026 & TTGAGTTTTTCGCTAATATCAG & 22 \\
\hline ico-vertex-FL-027 & CATATTTTTTTCCTGATTATCCAGTACCTTTTTTTTTACATCGGGAGAA & 49 \\
\hline ico-vertex-FL-028 & GCGCAACAGTACATAATTTTTATCAATATATGT & 33 \\
\hline ico-vertex-FL-029 & ATTTTTTTTTGCACCCAGCTAAACATAAAAACTTTTTAGGGAA & 43 \\
\hline ico-vertex-FL-030 & TCCTTTTTTTGAAAACATAGCTTTTTCAAATATTTTTTATTTTAGTTAA & 49 \\
\hline ico-vertex-FL-031 & GGCGTTTTTTTTTAGCGAACCCTTAATTGAGATTTTTATCGCCATATTT & 49 \\
\hline ico-vertex-FL-032 & TAGGATTTTTATCATTACCGCG & 22 \\
\hline ico-vertex-FL-033 & TATAATTTTTAGTACCGACAATCCTTATCATTTTTTTCCAAGAACGGGT & 49 \\
\hline ico-vertex-FL-034 & AAAAGTTTTTAAACGCAAAGAGCCATTTGGGATTTTTATTAGA & 43 \\
\hline
\end{tabular}




\begin{tabular}{|c|c|c|}
\hline ico-vertex-FL-035 & GCCAGTTAGCGTTTGCTTTTTCATCTTTTCATA & 33 \\
\hline ico-vertex-FL-036 & CCCTCTTTTTAGAACCGCCACAACTGGCATGATTTTTTTTAAGACTCCTT & 49 \\
\hline ico-vertex-AL-001 & ACTCACATTAATTGGGCGATGGCCCGTTAATA & 32 \\
\hline ico-vertex-AL-002 & AACCGTCTATCATATCGTAAAACT & 24 \\
\hline ico-vertex-AL-003 & GATGAACGGTATCTGTTGGGAAGGAGGCCGG & 31 \\
\hline ico-vertex-AL-004 & CAGGCTGCGCAATCATCTGCCAGT & 24 \\
\hline ico-vertex-AL-005 & TCGTAACCGTGTTGCGTTGCGCTCCAAAAAT & 31 \\
\hline ico-vertex-AL-006 & ATCGGCAAAATTTTATCAACAATATCACGCA & 31 \\
\hline ico-vertex-AL-007 & GAACGCGCCTGTTGGAGGCCGATT & 24 \\
\hline ico-vertex-AL-008 & GGAGCTAAACATAATATGCAACTACGGGCGC & 31 \\
\hline ico-vertex-AL-009 & CAACATGTTTTATAAGCACTAAATC & 24 \\
\hline ico-vertex-AL-010 & AGGTGCCGTAATCCCTTATAAAT & 31 \\
\hline ico-vertex-AL-011 & TTCCCAATTCTTTTTGAAAATCTCCACCTTTA & 24 \\
\hline ico-vertex-AL-012 & AATTTTTTTCACGTTAAGAGGAAGC & 31 \\
\hline ico-vertex-AL-013 & ATCAAAAAGATTCTAAATCGGTTGATAGCGT & 32 \\
\hline ico-vertex-AL-014 & CAGAGCATAAAGTCTACAAAGGCTAGCATCAA & 24 \\
\hline ico-vertex-AL-015 & TTTTTGAGAGATTGCGAACGAGTA & 31 \\
\hline ico-vertex-AL-016 & AGCCTTTATTTTTTGTGTCGAAATTAGCGAG & 24 \\
\hline ico-vertex-AL-017 & TCGCCTGATAAATCAACTAATGCA & 31 \\
\hline ico-vertex-AL-018 & AATACCACATTTATGCGCACGACTATTTTTAA & 24 \\
\hline ico-vertex-AL-019 & GGTTGTGAATTCTTGCTGCAAGGC & 23 \\
\hline ico-vertex-AL-020 & AAAGGGGGATGTCAACGCAAGGA & 31 \\
\hline ico-vertex-AL-021 & TCCCGCCAAAATAACCTACCATATGAAGTAT & 24 \\
\hline ico-vertex-AL-022 & TGGAAGGGTTAGTCAGTTGAAAGG & 31 \\
\hline ico-vertex-AL-023 & TGGCAAATCAATGGTGCTTGTTACGCAGAAG & 32 \\
\hline ico-vertex-AL-024 & CTTAAGCTACGTTAAACGGCGGATTATATAGG & 24 \\
\hline ico-vertex-AL-025 & CTCCGTGGGAACTTAACCCCGCTT & 31 \\
\hline ico-vertex-AL-026 & TCGTAATCATGTACCTTTTTAACCGTCTTTA & 24 \\
\hline ico-vertex-AL-027 & GTCTGAGAGACTTCAGTAATAAAA & 31 \\
\hline ico-vertex-AL-028 & AGTCACACGACTCCACGCTGGTTTGAAGAAC & 24 \\
\hline ico-vertex-AL-029 & GCAGCAAGCGGTTCGGCCAACGCG & 23 \\
\hline ico-vertex-AL-030 & CATTAATGAATTGTCATAGCTGT & 31 \\
\hline ico-vertex-AL-031 & CACCAGTACAATGCACCGTAATCAAGGTGTA & 31 \\
\hline ico-vertex-AL-032 & CCATCGATAGCATGGGATCGTCACCATTAGCG & 32 \\
\hline ico-vertex-AL-033 & GGCCGCTTTTGCTTTTCGAGGTGA & 24 \\
\hline
\end{tabular}




\begin{tabular}{|c|c|c|}
\hline ico-vertex-AL-034 & TATCAGCTTGCTTGGTTGCTTTGAATGGGAT & 31 \\
\hline ico-vertex-AL-035 & GGGCGCGTACTATACTACAACGCC & 24 \\
\hline ico-vertex-AL-036 & GCTACAGAGGCTACAGTTAATGC & 23 \\
\hline ico-vertex-AL-037 & TGCCCGTATAATACGTAACAAAGCACAAACA & 31 \\
\hline ico-vertex-AL-038 & TTACCCAAATCATATAAGGGAACC & 24 \\
\hline ico-vertex-AL-039 & GACGGTCAATCTCAAAAATCAGGTAGAATAC & 31 \\
\hline ico-vertex-AL-040 & ATGACCATAAATTTTTGAGGACTA & 24 \\
\hline ico-vertex-AL-041 & CAGAACGAGTATGAAGCCCTTTTTACCAGAG & 31 \\
\hline ico-vertex-AL-042 & AGCTATCTTACCTCCTGAGCAAAAGAGGGTAA & 32 \\
\hline ico-vertex-AL-043 & TCATTTCAATTATGTTTAACGTCA & 24 \\
\hline ico-vertex-AL-044 & TAGATTTTCAGTCTAACGGAACAATTATCAT & 31 \\
\hline ico-vertex-AL-045 & TAATAAAACGAATGTAAATTGGGC & 24 \\
\hline ico-vertex-AL-046 & AAAAATCTAAAGTTCATTTGAATT & 24 \\
\hline ico-vertex-AL-047 & ATTTAACAATTTGAAAATAGCAG & 23 \\
\hline ico-vertex-AL-048 & ACGTCAAAAATTCCGGAATCATAAAGTTGCT & 31 \\
\hline ico-vertex-AL-049 & TAAGAATAAACATATCGCAAGACA & 24 \\
\hline ico-vertex-AL-050 & ATGCAAATCCATCATCACCTTGCTCTTAGAA & 31 \\
\hline ico-vertex-AL-051 & AATTCTTACCATAAAGGGCGACATAACGCGA & 31 \\
\hline ico-vertex-AL-052 & GCGCCAAAGACATTCAGGGATAGCATTCATCG & 32 \\
\hline ico-vertex-AL-053 & CCACCCTCATTTTAGAAACCAATC & 24 \\
\hline ico-vertex-AL-054 & TACGAGCATGTTCATTTTGACGCTAAGAGAA & 31 \\
\hline ico-vertex-AL-055 & TGGAAATACCTATGTATAAAGCCA & 24 \\
\hline ico-vertex-AL-056 & GCGCGTTTTCATGGTGAATTATC & 23 \\
\hline ico-vertex-AL-057 & GCTTTTGATGATTTCGGCATTTTC & 24 \\
\hline ico-vertex-AL-058 & AAACCGAGGAATACAGGAGTGTACGCCGCCA & 31 \\
\hline ico-vertex-AL-059 & CCAGTTACAAAATACGCAATAATA & 24 \\
\hline ico-vertex-AL-060 & TATTCATTAAATTAAACAGCCATAAACATAT & 31 \\
\hline ico-FL-S1-001 & TATTTAAAAAACAGGAACGTCAAAGGGCGAAA & 32 \\
\hline ico-FL-S1-002 & GCGAGCTGTTTAGCTACCGGAGAGGGTAGCTA & 32 \\
\hline ico-FL-S1-003 & TTCAAAAGCAGCTTTCAGCGCCATTCGCCATT & 32 \\
\hline ico-FL-S1-004 & TCGTCGGTGCGGCCCTAACAACCCGTCGGATT & 32 \\
\hline ico-FL-S1-005 & CCAATAGGTTGTTAAACCTAATGAGTGAGCTA & 32 \\
\hline ico-FL-S1-006 & AAGAAAGCGCGAACGTATATAATGCTGTAGCT & 32 \\
\hline ico-FL-S1-007 & AAAATGTTATCCAATATTAAGCAATAAAGCCT & 32 \\
\hline ico-FL-S1-008 & TGCCCGAAACGACGGCGGATGTTCTTCTAAGT & 32 \\
\hline
\end{tabular}




\begin{tabular}{|c|c|c|}
\hline ico-FL-S1-009 & ACCGAACGACATAAATTAATGAGTAAACAGGG & 32 \\
\hline ico-FL-S1-010 & ATCACTTGCACCAGTGTGGCCCTGAGAGAGTT & 32 \\
\hline ico-FL-S1-011 & TAAAAGAGTTTATAATATGTTCAGCTAATGCA & 32 \\
\hline ico-FL-S1-012 & TAAATGAATTTTGTCGTTAATGCGCCGCTACA & 32 \\
\hline ico-FL-S1-013 & GTCAGGATCAGACCGGAGGAATTGCGAATAAT & 32 \\
\hline ico-FL-S1-014 & AAACGAAATGCCACTAAGTTCAGAAAACGAGA & 32 \\
\hline ico-FL-S1-015 & ACGATAAAATCATAACACGGAGATTTGTATCA & 32 \\
\hline ico-FL-S1-016 & ACCAGAAGGATTTTAAGAAGAAAAATCTACGT & 32 \\
\hline ico-FL-S1-017 & TACATTTGTAGATTAGTTATACTTCTGAATAA & 32 \\
\hline ico-FL-S1-018 & TATTAATTAACCTTGCGAGCCAGCAGCAAATG & 32 \\
\hline ico-FL-S1-019 & TTTTGAATAAGAATACTTTATCAAAATCATAG & 32 \\
\hline ico-FL-S1-020 & TTTTCGAGCAACATGTACAGGAAAAACGCTCA & 32 \\
\hline ico-FL-S1-021 & GCAAGCCGAAGTACCGGCCACCCTCAGAGCCA & 32 \\
\hline ico-FL-S1-022 & CAAGAGAAACCATCGCCTTGCAGGGAGTTAAA & 32 \\
\hline ico-FL-S1-023 & ATTGGCCTGCGCATAGAAGAACCGGATATTCA & 32 \\
\hline ico-FL-S1-024 & CCCTGAACGGATTCGCCGCAGAGGCGAATTAT & 32 \\
\hline ico-FL-S1-025 & GCCTTAAATCTGACCTTAAATAAGGCGTTAAA & 32 \\
\hline ico-FL-S1-026 & AAGTATAGAAGTGCCGAACGTCACCAATGAAA & 32 \\
\hline ico-FL-S1-027 & AACCGCCTCACCGGAAGTAAGCGTCATACATG & 32 \\
\hline ico-FL-S1-028 & CGCCACCACCCACAAGACAATGAAATAGCAAT & 32 \\
\hline ico-FL-S1-029 & CATACATAGTATGTTATCCAGAGCCTAATTTG & 32 \\
\hline ico-FL-S1-030 & TATCCGGTCAAGCAAATTCATATGGTTTACCA & 32 \\
\hline ico-AL-S1-001 & $\begin{array}{l}\text { CCCAAATCGGACTCCAAGATTGTACACTATTAAAAGGGAGGTTTGGAATG } \\
\text { GGGTCG }\end{array}$ & 56 \\
\hline ico-AL-S1-002 & $\begin{array}{l}\text { GAGTCTGGAATTAATGTATTTTCAACCGTTCTAATCATATATCAATATAGAG } \\
\text { AATC }\end{array}$ & 56 \\
\hline ico-AL-S1-003 & $\begin{array}{l}\text { TCTTCGCTCCAGGCAACGGCACCGCTTCTGGTTGGGTAACGCCTGAGTA } \\
\text { GCTGGCG }\end{array}$ & 56 \\
\hline ico-AL-S1-004 & $\begin{array}{l}\text { GTCACGTTGAGCGAGTGCCATCTGCATCAACAACGACGACTCCTGTAGTG } \\
\text { GGCGCA }\end{array}$ & 56 \\
\hline ico-AL-S1-005 & $\begin{array}{l}\text { TCGGGAAACTGGGGTGTCAGCTCAGCATAAAGGGCGGTTTAACATACGG } \\
\text { CCAGCTG }\end{array}$ & 56 \\
\hline ico-AL-S1-006 & $\begin{array}{l}\text { AGTTTCATATTGCTGAGGCGAGAAGATGGCTTTTGACCATAGAGGTCAAC } \\
\text { AGTTGA }\end{array}$ & 56 \\
\hline ico-AL-S1-007 & $\begin{array}{l}\text { ACCCTGTATAGCAAAAAATCATACAGGCAAGGTTTAGAACAGTTTTGCGC } \\
\text { GGGAGA }\end{array}$ & 56 \\
\hline ico-AL-S1-008 & $\begin{array}{l}\text { TGAATTGTGCCAGGGTCAGTGCCAAGCTTTCTTTTACGCTTTCGACAATGA } \\
\text { CAATG }\end{array}$ & 56 \\
\hline
\end{tabular}




\begin{tabular}{|c|c|c|}
\hline ico-AL-S1-009 & $\begin{array}{l}\text { GATCCCCGGGTTGGTGCATTTCTCCGAACTCTTGAAATTGCCCTAAAAGC } \\
\text { TCGAAT }\end{array}$ & 56 \\
\hline ico-AL-S1-010 & $\begin{array}{l}\text { ATCCTGTTTCACCGCCAGACGGGCAACAGCTGTAGCCCGAAATACTTCGT } \\
\text { TCCGAA }\end{array}$ & 56 \\
\hline ico-AL-S1-011 & $\begin{array}{l}\text { GAAAAATATAAACAACCAGTGAGGGTCCAGACGCTGTCTTAAGGTAAATC } \\
\text { CTAATT }\end{array}$ & 56 \\
\hline ico-AL-S1-012 & $\begin{array}{l}\text { GCTTTCCTCGCCGCGCTCTTTCCAGCGTAACCTTTAGACAGTAGCGGTTC } \\
\text { AGAGCG }\end{array}$ & 56 \\
\hline ico-AL-S1-013 & $\begin{array}{l}\text { AAGGAGCCACAACTAAAAGCAAACGTGAGAATAACAGCTTCAACAGTTTA } \\
\text { TCGGTT }\end{array}$ & 56 \\
\hline ico-AL-S1-014 & $\begin{array}{l}\text { ATAGTCAGCTTTAAACCGAAGGCAGAATCCCCCTTCAAATGTCATAAACG } \\
\text { GATTGC }\end{array}$ & 56 \\
\hline ico-AL-S1-015 & $\begin{array}{l}\text { GTTACTTAAAAGTACACCTCGTTTATACCAAGCAACTTTGTTGACCCCGAG } \\
\text { GCGCA }\end{array}$ & 56 \\
\hline ico-AL-S1-016 & $\begin{array}{l}\text { AAGATTCAGACGTTGGGAACTGGCTCATTATAACGCCAAAATCATTTTGAT } \\
\text { TTAGG }\end{array}$ & 56 \\
\hline ico-AL-S1-017 & $\begin{array}{l}\text { TAAAACAGTGTTTGGAAGCCGTCATCAATATATACAGTAAAGATGATGAAA } \\
\text { TTGCG }\end{array}$ & 56 \\
\hline ico-AL-S1-018 & $\begin{array}{l}\text { ACCCTCAACACGCTGATTCTGTAACCGCCTGCAAGGTTATGCGGTCAGTG } \\
\text { GTCAGT }\end{array}$ & 56 \\
\hline ico-AL-S1-019 & $\begin{array}{l}\text { TTATATAAATAGTGAAGTGGCACAACGCTGAGGAGAAAACGATAGCTTAA } \\
\text { ATGCTG }\end{array}$ & 56 \\
\hline ico-AL-S1-020 & $\begin{array}{l}\text { ATTATTTACCATTGCAAATTTAGGACAATATTCTGGCCAAGCTGGTAAGAT } \\
\text { TCACC }\end{array}$ & 56 \\
\hline ico-AL-S1-021 & $\begin{array}{l}\text { ATGTACCGTCAGAACCCACTCATCCTCAGAACTCCACAGAGTTTAGTAAG } \\
\text { TTTCGT }\end{array}$ & 56 \\
\hline ico-AL-S1-022 & $\begin{array}{l}\text { AGCATCGGCGCTGAGGCCACGCATAACCGATATTCATGAGAAGTATTATA } \\
\text { GCAACG }\end{array}$ & 56 \\
\hline ico-AL-S1-023 & $\begin{array}{l}\text { AAGGCTTGATCTTGACGCTGGCTGACCTTCATGTTTAATTCAGGAGGTAG } \\
\text { AAACAC }\end{array}$ & 56 \\
\hline ico-AL-S1-024 & $\begin{array}{l}\text { CATCAAGACAAAATCGCTGATTGCTTTGAATATAATGGAATTAGACGGTTA } \\
\text { ATTAC }\end{array}$ & 56 \\
\hline ico-AL-S1-025 & $\begin{array}{l}\text { GTTTAGTACCGTGTGAAAATTTAATGGTTTGACAGTAGGGTCCCGACTGTT } \\
\text { ATACA }\end{array}$ & 56 \\
\hline ico-AL-S1-026 & $\begin{array}{l}\text { GTTTGCCTAGGCCGGATCGAGAGGACCATTACCCCCCTTACAAAATCAAG } \\
\text { ACTGTA }\end{array}$ & 56 \\
\hline ico-AL-S1-027 & $\begin{array}{l}\text { CGGGGTCACCGTTCCACCAGAGCCGCAGTCTCTATTTCGGAGCCAGAAA } \\
\text { GTAACAG }\end{array}$ & 56 \\
\hline ico-AL-S1-028 & $\begin{array}{l}\text { TAGCCGAAAGCAAGAAAATTGAGTTAAGCCCACCCAAAAGCCTCAGAGCC } \\
\text { AGAAGG }\end{array}$ & 56 \\
\hline ico-AL-S1-029 & $\begin{array}{l}\text { AAATAAGAAGCGTCTTGCAAACGTCTTACCAAGAGAGAATCAATTTTATTT } \\
\text { GTTTA }\end{array}$ & 56 \\
\hline ico-AL-S1-030 & $\begin{array}{l}\text { GGGAAGGTATAGAAAATCAGATATTATTTTGTCGACTTGACACCACGGAC } \\
\text { GGAAAT }\end{array}$ & 56 \\
\hline
\end{tabular}




\begin{tabular}{|c|c|c|}
\hline ico-AL-S2-001 & AGCCCCAATTGTAAACACTACGTGAACCATCA & 32 \\
\hline ico-AL-S2-002 & ATAACCTGAAAAGGTGTCAGGTCATTGCCTGA & 32 \\
\hline ico-AL-S2-003 & ACTCCAGCGGTGAGAAGCGATCGGTGCGGGCC & 32 \\
\hline ico-AL-S2-004 & CCGACAGTGGGCACGAGACCGTAATGGGATAG & 32 \\
\hline ico-AL-S2-005 & TTAAATTTAACGCCATACTGCCCGCTTTCCAG & 32 \\
\hline ico-AL-S2-006 & GAAAGCCGGAAAGGAGAAGTACGGTGTCTGGA & 32 \\
\hline ico-AL-S2-007 & GCATTAACTAGACTGGTACCAAAAACATTATG & 32 \\
\hline ico-AL-S2-008 & GTTGTAAACGTTATTATAAGTGTCCTTAGTGC & 32 \\
\hline ico-AL-S2-009 & CGCATTTCAACCACCACTCGATAAAGACGGAG & 32 \\
\hline ico-AL-S2-010 & TTTCTTTTCCTGAGTAGCCCCAGCAGGCGAAA & 32 \\
\hline ico-AL-S2-011 & GAAGTGTTTCTGTCCAGATAAGTCCTGAACAA & 32 \\
\hline ico-AL-S2-012 & ATCTAAAGTTTTCTGTCGAGCACGTATAACGT & 32 \\
\hline ico-AL-S2-013 & AAGCGAACTAGAGAGTAAAAAAAAGGCTCCAA & 32 \\
\hline ico-AL-S2-014 & ATACGTAAGAGGCAAACTTTACCCTGACTATT & 32 \\
\hline ico-AL-S2-015 & GCAACACTAACCAAAACCGCGACCTGCTCCAT & 32 \\
\hline ico-AL-S2-016 & CCTTATGCGAGCGGAACATTATTACAGGTAGA & 32 \\
\hline ico-AL-S2-017 & ACAACTAAAGGATTTACAAAATTATTTGCACG & 32 \\
\hline ico-AL-S2-018 & GAGTGAATAATTTTCCGAACCTCAAATATCAA & 32 \\
\hline ico-AL-S2-019 & GAAAGCGTGGCTATTATCCGGCTTAGGTTGGG & 32 \\
\hline ico-AL-S2-020 & AACAACGCCCAGTAATCAATCGTCTGAAATGG & 32 \\
\hline ico-AL-S2-021 & ATTAAACCTTTTTAATTAGCCCAATAGGAACCC & 32 \\
\hline ico-AL-S2-022 & TGACAACAGGATTAGGCTCAGCAGCGAAAGAC & 32 \\
\hline ico-AL-S2-023 & CAGACCAGTGATATTCTGCTCATTCAGTGAAT & 32 \\
\hline ico-AL-S2-024 & ACAATAACAAAGTCAGAAGATGATGAAACAAA & 32 \\
\hline ico-AL-S2-025 & TTTCATCTTCAAGATTTTACTAGAAAAAGCCT & 32 \\
\hline ico-AL-S2-026 & AGGCGGATCCCGGAATGTAGCGACAGAATCAA & 32 \\
\hline ico-AL-S2-027 & ATCAAAATCCCTCAGATGGTAATAAGTTTTAA & 32 \\
\hline ico-AL-S2-028 & AGAGATAAGAACCACCAAGAAAAGTAAGCAGA & 32 \\
\hline ico-AL-S2-029 & ATTACGCAAAGGTGGCTTATTTATCCCAATCC & 32 \\
\hline ico-AL-S2-030 & CCCAATAGATTCTAAGTCAACCGATTGAGGGA & 32 \\
\hline ico-FL-S2-001 & GGAACCCTAAGAACGTAAGTTTTTCAAGAGTCTAAGCAAA & 40 \\
\hline ico-FL-S2-002 & AGCATGTCAGCTGATAAGCAAACAGATATTCATTTGGGGC & 40 \\
\hline ico-FL-S2-003 & GATTAAGTGCCGGAAAATTACGCCAATGTGTAGGTAAAGA & 40 \\
\hline ico-FL-S2-004 & TTGAGGGGTTAAATGTGGTGTAGACCAGCTTTTAAGCAAC & 40 \\
\hline ico-FL-S2-005 & CGGGGAGATGTAAAGCCCTGTCGTAGCCGGAATTTTTTAA & 40 \\
\hline
\end{tabular}




\begin{tabular}{|c|c|c|}
\hline ico-FL-S2-006 & GATTTAGTAGAGCTTATCCATATATTTTTGCGAGGAAGGG & 40 \\
\hline ico-FL-S2-007 & TAAAAATTCAAAGAATATACTTTTCAGAGGGGGTAATAGT & 40 \\
\hline ico-FL-S2-008 & CTAATCTACAGGAGAACAACCTTACTCGTATTAAATCCTT & 40 \\
\hline ico-FL-S2-009 & TTCCTGTGGACCTCCTGGTACCGACATCGCCATTAAAAAT & 40 \\
\hline ico-FL-S2-010 & CAAAAGAAATTGCCCTTGATGGTGTTTGATTAGTAATAAC & 40 \\
\hline ico-FL-S2-011 & AATAATCGGACGACAAATATCCCAGTAATTCTCCACCGAG & 40 \\
\hline ico-FL-S2-012 & AAAGGGATACCACACCCGTTAGAACACGCTGCGACGTTAG & 40 \\
\hline ico-FL-S2-013 & ATTTCTTAAGAAAGGATTTAATTGTCAGCGGATCCAACAG & 40 \\
\hline ico-FL-S2-014 & CCGAAAGACTCAAATGAAGCAAAGTATTCATTCCAACCTA & 40 \\
\hline ico-FL-S2-015 & GAACTGACCGCGAAACGCCGGAACCAGCGATTACCAGACG & 40 \\
\hline ico-FL-S2-016 & GATACATACCAGTCAGTCAGTTGAGCGGAACAAAGAAACC & 40 \\
\hline ico-FL-S2-017 & GATGAATAATCCTGATAAATAAAGGCAATTCAATAGATAA & 40 \\
\hline ico-FL-S2-018 & AATTGAGGAACAGTGCTCAATATCTATTAACAATCGTCGC & 40 \\
\hline ico-FL-S2-019 & AAGAACGCAAGAGTCACTATATGTAGATTAAGGACAATAT & 40 \\
\hline ico-FL-S2-020 & GGGACATTACCGCCAGCATTGGCATATCCAGACAGAGGCA & 40 \\
\hline ico-FL-S2-021 & TGTAGCATCGCCACCCTAACACTGCCGCCACCGAGAACAA & 40 \\
\hline ico-FL-S2-022 & AAGACTTTTATTCGGTAACGAGGGAGAGGCTGAGACTCCT & 40 \\
\hline ico-FL-S2-023 & TTGAGATGCAAGAGTACCCTGACGTGAGGCAGGTCAGACG & 40 \\
\hline ico-FL-S2-024 & ACCTTTTTCCAAGTTAAAACAAAAGAGAATTAACTGAACA & 40 \\
\hline ico-FL-S2-025 & ACGCTCAAAATACCGATCATATGCTGCGGGAGGTTTTGAA & 40 \\
\hline ico-FL-S2-026 & $\begin{array}{l}\text { GGTCATAGCATTAGCATTAGCGTCCCAGTAGCGTTGATAT } \\
\end{array}$ & 40 \\
\hline ico-FL-S2-027 & CCCCTGCCTGAATTTAGTGCCTTGTGGAAAGCACCACCGG & 40 \\
\hline ico-FL-S2-028 & ACGGAATAATAATAAGCAAAGTTACCACCACCCTCAGAGC & 40 \\
\hline ico-FL-S2-029 & CCTTTACACGCTAACGAACGATTTTCCTGAATAGAAAATA & 40 \\
\hline ico-FL-S2-030 & ACCGTCACCACAATCAAAATATTGAATAAGTTAGAAGGCT & 40 \\
\hline $\begin{array}{l}\text { ico-AL-S2-anchor- } \\
10-001\end{array}$ & TTAGCCCCAATTGTAAACACTACGTGAACCATCAAGTACCTCGC & 44 \\
\hline $\begin{array}{l}\text { ico-AL-S2-anchor- } \\
10-002\end{array}$ & TTATAACCTGAAAAGGTGTCAGGTCATTGCCTGAGAAAGGTCGC & 44 \\
\hline $\begin{array}{l}\text { ico-AL-S2-anchor- } \\
10-003\end{array}$ & TTACTCCAGCGGTGAGAAGCGATCGGTGCGGGCCGTTGAACAGC & 44 \\
\hline $\begin{array}{l}\text { ico-AL-S2-anchor- } \\
10-004\end{array}$ & TTCCGACAGTGGGCACGAGACCGTAATGGGATAGCAGCGACGAG & 44 \\
\hline $\begin{array}{l}\text { ico-AL-S2-anchor- } \\
10-005\end{array}$ & TTTTAAATTTAACGCCATACTGCCCGCTTTCCAGGGACGCTCGA & 44 \\
\hline $\begin{array}{l}\text { ico-AL-S2-anchor- } \\
10-006\end{array}$ & TTGAAAGCCGGAAAGGAGAAGTACGGTGTCTGGAGATAAAACTC & 44 \\
\hline
\end{tabular}




\begin{tabular}{|c|c|c|}
\hline $\begin{array}{l}\text { ico-AL-S2-anchor- } \\
10-007\end{array}$ & TTGCATTAACTAGACTGGTACCAAAAACATTATGTAATAACCTG & 44 \\
\hline $\begin{array}{l}\text { ico-AL-S2-anchor- } \\
10-008\end{array}$ & TTGTTGTAAACGTTATTATAAGTGTCCTTAGTGCACCCCTCAGC & 44 \\
\hline $\begin{array}{l}\text { ico-AL-S2-anchor- } \\
10-009\end{array}$ & TTCGCATTTCAACCACCACTCGATAAAGACGGAGTTTATAGGTC & 44 \\
\hline $\begin{array}{l}\text { ico-AL-S2-anchor- } \\
10-010\end{array}$ & TTTTTCTTTTCCTGAGTAGCCCCAGCAGGCGAAAGGTAATAAGA & 44 \\
\hline $\begin{array}{l}\text { ico-AL-S2-anchor- } \\
10-011\end{array}$ & TTGAAGTGTTTCTGTCCAGATAAGTCCTGAACAAAACACCATCC & 44 \\
\hline $\begin{array}{l}\text { ico-AL-S2-anchor- } \\
10-012\end{array}$ & TTATCTAAAGTTTTCTGTCGAGCACGTATAACGTGCAAGGTCCA & 44 \\
\hline $\begin{array}{l}\text { ico-AL-S2-anchor- } \\
10-013\end{array}$ & TTAAGCGAACTAGAGAGTAAAAAAAAGGCTCCAAGGCGTCGCGT & 44 \\
\hline $\begin{array}{l}\text { ico-AL-S2-anchor- } \\
10-014\end{array}$ & TTATACGTAAGAGGCAAACTTTACCCTGACTATTATGCCTACAG & 44 \\
\hline $\begin{array}{l}\text { ico-AL-S2-anchor- } \\
10-015\end{array}$ & TTGCAACACTAACCAAAACCGCGACCTGCTCCATCAGTCGGGAG & 44 \\
\hline $\begin{array}{l}\text { ico-AL-S2-anchor- } \\
10-016\end{array}$ & TTCCTTATGCGAGCGGAACATTATTACAGGTAGATATCAAAATA & 44 \\
\hline $\begin{array}{l}\text { ico-AL-S2-anchor- } \\
10-017\end{array}$ & TTACAACTAAAGGATTTACAAAATTATTTGCACGATCATGGTGG & 44 \\
\hline $\begin{array}{l}\text { ico-AL-S2-anchor- } \\
10-018\end{array}$ & TTGAGTGAATAATTTTCCGAACCTCAAATATCAAAGAAATTTCA & 44 \\
\hline $\begin{array}{l}\text { ico-AL-S2-anchor- } \\
10-019\end{array}$ & TTGAAAGCGTGGCTATTATCCGGCTTAGGTTGGGATCACGTTCT & 44 \\
\hline $\begin{array}{l}\text { ico-AL-S2-anchor- } \\
10-020\end{array}$ & TTAACAACGCCCAGTAATCAATCGTCTGAAATGGATTAGGGTTA & 44 \\
\hline $\begin{array}{l}\text { ico-AL-S2-anchor- } \\
10-021\end{array}$ & TTATTAAACCTTTTTATTAGCCCAATAGGAACCCTTTTGCAAGC & 44 \\
\hline $\begin{array}{l}\text { ico-AL-S2-anchor- } \\
10-022\end{array}$ & TTTGACAACAGGATTAGGCTCAGCAGCGAAAGACCCACCAAGTC & 44 \\
\hline $\begin{array}{l}\text { ico-AL-S2-anchor- } \\
10-023\end{array}$ & TTCAGACCAGTGATATTCTGCTCATTCAGTGAATTCGGAAACCT & 44 \\
\hline $\begin{array}{l}\text { ico-AL-S2-anchor- } \\
10-024\end{array}$ & TTACAATAACAAAGTCAGAAGATGATGAAACAAACCAAGATTTG & 44 \\
\hline $\begin{array}{l}\text { ico-AL-S2-anchor- } \\
10-025\end{array}$ & TTTTTCATCTTCAAGATTTTACTAGAAAAAGCCTCGGTGGTCTA & 44 \\
\hline $\begin{array}{l}\text { ico-AL-S2-anchor- } \\
10-026\end{array}$ & TTAGGCGGATCCCGGAATGTAGCGACAGAATCAACGACCCTCGG & 44 \\
\hline $\begin{array}{l}\text { ico-AL-S2-anchor- } \\
10-027\end{array}$ & TTATCAAAATCCCTCAGATGGTAATAAGTTTTAATCGGCAATCT & 44 \\
\hline $\begin{array}{l}\text { ico-AL-S2-anchor- } \\
10-028\end{array}$ & TTAGAGATAAGAACCACCAAGAAAAGTAAGCAGAACGACATTAG & 44 \\
\hline
\end{tabular}




\begin{tabular}{|c|c|c|}
\hline $\begin{array}{l}\text { ico-AL-S2-anchor- } \\
10-029\end{array}$ & TTATTACGCAAAGGTGGCTTATTTATCCCAATCCATCTCTTCCA & 44 \\
\hline $\begin{array}{l}\text { ico-AL-S2-anchor- } \\
10-030\end{array}$ & TTCCCAATAGATTCTAAGTCAACCGATTGAGGGACTACGCGATT & 44 \\
\hline $\begin{array}{l}\text { ico-AL-S2-anchor- } \\
20-001\end{array}$ & $\begin{array}{l}\text { TTAGCCCCAATTGTAAACACTACGTGAACCATCAGCTTGCCTTTAGTACCT } \\
\text { CGC }\end{array}$ & 54 \\
\hline $\begin{array}{l}\text { ico-AL-S2-anchor- } \\
20-002\end{array}$ & $\begin{array}{l}\text { TTATAACCTGAAAAGGTGTCAGGTCATTGCCTGAAGTTGATGGCGAAAGG } \\
\text { TCGC }\end{array}$ & 54 \\
\hline $\begin{array}{l}\text { ico-AL-S2-anchor- } \\
20-003\end{array}$ & $\begin{array}{l}\text { TTACTCCAGCGGTGAGAAGCGATCGGTGCGGGCCCCTATTAGTGGTTGA } \\
\text { ACAGC }\end{array}$ & 54 \\
\hline $\begin{array}{l}\text { ico-AL-S2-anchor- } \\
20-004\end{array}$ & $\begin{array}{l}\text { TTCCGACAGTGGGCACGAGACCGTAATGGGATAGAGCCTCAACGCAGCG } \\
\text { ACGAG }\end{array}$ & 54 \\
\hline $\begin{array}{l}\text { ico-AL-S2-anchor- } \\
20-005\end{array}$ & $\begin{array}{l}\text { TTTTAAATTTAACGCCATACTGCCCGCTTTCCAGGGCTTTAACCGGACGCT } \\
\text { CGA }\end{array}$ & 54 \\
\hline $\begin{array}{l}\text { ico-AL-S2-anchor- } \\
20-006\end{array}$ & $\begin{array}{l}\text { TTGAAAGCCGGAAAGGAGAAGTACGGTGTCTGGATCATGGAAGCGATAA } \\
\text { AACTC }\end{array}$ & 54 \\
\hline $\begin{array}{l}\text { ico-AL-S2-anchor- } \\
20-007\end{array}$ & $\begin{array}{l}\text { TTGCATTAACTAGACTGGTACCAAAAACATTATGATAATCTCTTTAATAACC } \\
\text { TG }\end{array}$ & 54 \\
\hline $\begin{array}{l}\text { ico-AL-S2-anchor- } \\
20-008\end{array}$ & $\begin{array}{l}\text { TTGTTGTAAACGTTATTATAAGTGTCCTTAGTGCCGCTTGGTCAACCCCTC } \\
\text { AGC }\end{array}$ & 54 \\
\hline $\begin{array}{l}\text { ico-AL-S2-anchor- } \\
20-009\end{array}$ & $\begin{array}{l}\text { TTCGCATTTCAACCACCACTCGATAAAGACGGAGGCACAGAATGTTTATA } \\
\text { GGTC }\end{array}$ & 54 \\
\hline $\begin{array}{l}\text { ico-AL-S2-anchor- } \\
20-010\end{array}$ & $\begin{array}{l}\text { TTTTTCTTTTCCTGAGTAGCCCCAGCAGGCGAAATAGTTGAAATGGTAATA } \\
\text { AGA }\end{array}$ & 54 \\
\hline $\begin{array}{l}\text { ico-AL-S2-anchor- } \\
20-011\end{array}$ & $\begin{array}{l}\text { TTGAAGTGTTTCTGTCCAGATAAGTCCTGAACAAGAGTGGCATTAACACCA } \\
\text { TCC }\end{array}$ & 54 \\
\hline $\begin{array}{l}\text { ico-AL-S2-anchor- } \\
20-012\end{array}$ & $\begin{array}{l}\text { TTATCTAAAGTTTTCTGTCGAGCACGTATAACGTACCTTTAGCAGCAAGGT } \\
\text { CCA }\end{array}$ & 54 \\
\hline $\begin{array}{l}\text { ico-AL-S2-anchor- } \\
20-013\end{array}$ & $\begin{array}{l}\text { TTAAGCGAACTAGAGAGTAAAAAAAAGGCTCCAACTGGTTGAACGGCGTC } \\
\text { GCGT }\end{array}$ & 54 \\
\hline $\begin{array}{l}\text { ico-AL-S2-anchor- } \\
20-014\end{array}$ & $\begin{array}{l}\text { TTATACGTAAGAGGCAAACTTTACCCTGACTATTAGCATCACCCATGCCTA } \\
\text { CAG }\end{array}$ & 54 \\
\hline $\begin{array}{l}\text { ico-AL-S2-anchor- } \\
20-015\end{array}$ & $\begin{array}{l}\text { TTGCAACACTAACCAAAACCGCGACCTGCTCCATACATCATAGGCAGTCG } \\
\text { GGAG }\end{array}$ & 54 \\
\hline $\begin{array}{l}\text { ico-AL-S2-anchor- } \\
20-016\end{array}$ & $\begin{array}{l}\text { TTCCTTATGCGAGCGGAACATTATTACAGGTAGAACCGTCAAACTATCAAA } \\
\text { ATA }\end{array}$ & 54 \\
\hline $\begin{array}{l}\text { ico-AL-S2-anchor- } \\
20-017\end{array}$ & $\begin{array}{l}\text { TTACAACTAAAGGATTTACAAAATTATTTGCACGACTGGTCATAATCATGG } \\
\text { TGG }\end{array}$ & 54 \\
\hline $\begin{array}{l}\text { ico-AL-S2-anchor- } \\
20-018\end{array}$ & $\begin{array}{l}\text { TTGAGTGAATAATTTTCCGAACCTCAAATATCAACATCCTTCATAGAAATTT } \\
\text { CA }\end{array}$ & 54 \\
\hline $\begin{array}{l}\text { ico-AL-S2-anchor- } \\
20-019\end{array}$ & $\begin{array}{l}\text { TTGAAAGCGTGGCTATTATCCGGCTTAGGTTGGGGCATGAAGTAATCACG } \\
\text { TTCT }\end{array}$ & 54 \\
\hline $\begin{array}{l}\text { ico-AL-S2-anchor- } \\
20-020\end{array}$ & $\begin{array}{l}\text { TTAACAACGCCCAGTAATCAATCGTCTGAAATGGGATTAAGCTCATTAGG } \\
\text { GTTA }\end{array}$ & 54 \\
\hline
\end{tabular}




\begin{tabular}{|c|c|c|}
\hline $\begin{array}{l}\text { ico-AL-S2-anchor- } \\
20-021\end{array}$ & $\begin{array}{l}\text { TTATTAAACCTTTTTATTAGCCCAATAGGAACCCAGGCCACGTATTTTGCA } \\
\text { AGC }\end{array}$ & 54 \\
\hline $\begin{array}{l}\text { ico-AL-S2-anchor- } \\
20-022\end{array}$ & $\begin{array}{l}\text { TTTGACAACAGGATTAGGCTCAGCAGCGAAAGACGGCAGACTTGCCACC } \\
\text { AAGTC }\end{array}$ & 54 \\
\hline $\begin{array}{l}\text { ico-AL-S2-anchor- } \\
20-023\end{array}$ & $\begin{array}{l}\text { TTCAGACCAGTGATATTCTGCTCATTCAGTGAATGCGCATAATCTCGGAAA } \\
\text { CCT }\end{array}$ & 54 \\
\hline $\begin{array}{l}\text { ico-AL-S2-anchor- } \\
20-024\end{array}$ & $\begin{array}{l}\text { TTACAATAACAAAGTCAGAAGATGATGAAACAAAAAAAAAGCCTCCAAGAT } \\
\text { TTG }\end{array}$ & 54 \\
\hline $\begin{array}{l}\text { ico-AL-S2-anchor- } \\
20-025\end{array}$ & $\begin{array}{l}\text { TTTTTCATCTTCAAGATTTTACTAGAAAAAGCCTCCCTTCGGGGCGGTGGT } \\
\text { CTA }\end{array}$ & 54 \\
\hline $\begin{array}{l}\text { ico-AL-S2-anchor- } \\
20-026\end{array}$ & $\begin{array}{l}\text { TTAGGCGGATCCCGGAATGTAGCGACAGAATCAAATTAGCCTTGCGACCC } \\
\text { TCGG }\end{array}$ & 54 \\
\hline $\begin{array}{l}\text { ico-AL-S2-anchor- } \\
20-027\end{array}$ & $\begin{array}{l}\text { TTATCAAAATCCCTCAGATGGTAATAAGTTTTAAATTTTGCATCTCGGCAAT } \\
\text { CT }\end{array}$ & 54 \\
\hline $\begin{array}{l}\text { ico-AL-S2-anchor- } \\
20-028\end{array}$ & $\begin{array}{l}\text { TTAGAGATAAGAACCACCAAGAAAAGTAAGCAGAAGCATCAGTGACGACA } \\
\text { TTAG }\end{array}$ & 54 \\
\hline $\begin{array}{l}\text { ico-AL-S2-anchor- } \\
20-029\end{array}$ & $\begin{array}{l}\text { TTATTACGCAAAGGTGGCTTATTTATCCCAATCCAAAAGACAGAATCTCTT } \\
\text { CCA }\end{array}$ & 54 \\
\hline $\begin{array}{l}\text { ico-AL-S2-anchor- } \\
20-030\end{array}$ & $\begin{array}{l}\text { TTCCCAATAGATTCTAAGTCAACCGATTGAGGGAAGCAAAGCCTCTACGC } \\
\text { GATT }\end{array}$ & 54 \\
\hline $\begin{array}{l}\text { ico-AL-S2-anchor- } \\
30-001\end{array}$ & $\begin{array}{l}\text { TTAGCCCCAATTGTAAACACTACGTGAACCATCAGCGCCTTTACGCTTGC } \\
\text { CTTTAGTACCTCGC }\end{array}$ & 64 \\
\hline $\begin{array}{l}\text { ico-AL-S2-anchor- } \\
30-002\end{array}$ & $\begin{array}{l}\text { TTATAACCTGAAAAGGTGTCAGGTCATTGCCTGACAGAATCGTTAGTTGAT } \\
\text { GGCGAAAGGTCGC }\end{array}$ & 64 \\
\hline $\begin{array}{l}\text { ico-AL-S2-anchor- } \\
30-003\end{array}$ & $\begin{array}{l}\text { TTACTCCAGCGGTGAGAAGCGATCGGTGCGGGCCTGATTTCTTACCTATT } \\
\text { AGTGGTTGAACAGC }\end{array}$ & 64 \\
\hline $\begin{array}{l}\text { ico-AL-S2-anchor- } \\
30-004\end{array}$ & $\begin{array}{l}\text { TTCCGACAGTGGGCACGAGACCGTAATGGGATAGCATAAACGCAAGCCT } \\
\text { CAACGCAGCGACGAG }\end{array}$ & 64 \\
\hline $\begin{array}{l}\text { ico-AL-S2-anchor- } \\
30-005\end{array}$ & $\begin{array}{l}\text { TTTTAAATTTAACGCCATACTGCCCGCTTTCCAGACAATTCAGCGGCTTTA } \\
\text { ACCGGACGCTCGA }\end{array}$ & 64 \\
\hline $\begin{array}{l}\text { ico-AL-S2-anchor- } \\
30-006\end{array}$ & $\begin{array}{l}\text { TTGAAAGCCGGAAAGGAGAAGTACGGTGTCTGGAAACTTCTGCGTCATG } \\
\text { GAAGCGATAAAACTC }\end{array}$ & 64 \\
\hline $\begin{array}{l}\text { ico-AL-S2-anchor- } \\
\text { 30-007 }\end{array}$ & $\begin{array}{l}\text { TTGCATTAACTAGACTGGTACCAAAAACATTATGCTGGAGACAAATAATCT } \\
\text { CTTTAATAACCTG }\end{array}$ & 64 \\
\hline $\begin{array}{l}\text { ico-AL-S2-anchor- } \\
\text { 30-008 }\end{array}$ & $\begin{array}{l}\text { TTGTTGTAAACGTTATTATAAGTGTCCTTAGTGCTACCGCGCTTCGCTTGG } \\
\text { TCAACCCCTCAGC }\end{array}$ & 64 \\
\hline $\begin{array}{l}\text { ico-AL-S2-anchor- } \\
\text { 30-009 }\end{array}$ & $\begin{array}{l}\text { TTCGCATTTCAACCACCACTCGATAAAGACGGAGAAGAAACGCGGCACAG } \\
\text { AATGTTTATAGGTC }\end{array}$ & 64 \\
\hline $\begin{array}{l}\text { ico-AL-S2-anchor- } \\
30-010\end{array}$ & $\begin{array}{l}\text { TTTTTCTTTTCCTGAGTAGCCCCAGCAGGCGAAAATAACCGGAGTAGTTG } \\
\text { AAATGGTAATAAGA }\end{array}$ & 64 \\
\hline $\begin{array}{l}\text { ico-AL-S2-anchor- } \\
\text { 30-011 }\end{array}$ & $\begin{array}{l}\text { TTGAAGTGTTTCTGTCCAGATAAGTCCTGAACAAGTCGGGAGAGGAGTGG } \\
\text { CATTAACACCATCC }\end{array}$ & 64 \\
\hline $\begin{array}{l}\text { ico-AL-S2-anchor- } \\
30-012\end{array}$ & $\begin{array}{l}\text { TTATCTAAAGTTTTCTGTCGAGCACGTATAACGTTAGCTCCTAGACCTTTA } \\
\text { GCAGCAAGGTCCA }\end{array}$ & 64 \\
\hline
\end{tabular}




\begin{tabular}{|c|c|c|}
\hline $\begin{array}{l}\text { ico-AL-S2-anchor- } \\
30-013\end{array}$ & $\begin{array}{l}\text { TTAAGCGAACTAGAGAGTAAAAAAAAGGCTCCAAGCTTCAATATCTGGTTG } \\
\text { AACGGCGTCGCGT }\end{array}$ & 64 \\
\hline $\begin{array}{l}\text { ico-AL-S2-anchor- } \\
30-014\end{array}$ & $\begin{array}{l}\text { TTATACGTAAGAGGCAAACTTTACCCTGACTATTATTTAATACCAGCATCA } \\
\text { CCCATGCCTACAG }\end{array}$ & 64 \\
\hline $\begin{array}{l}\text { ico-AL-S2-anchor- } \\
30-015\end{array}$ & $\begin{array}{l}\text { TTGCAACACTAACCAAAACCGCGACCTGCTCCATCAAAGGATAAACATCA } \\
\text { TAGGCAGTCGGGAG }\end{array}$ & 64 \\
\hline $\begin{array}{l}\text { ico-AL-S2-anchor- } \\
30-016\end{array}$ & $\begin{array}{l}\text { TTCCTTATGCGAGCGGAACATTATTACAGGTAGAACCAGCATTAACCGTC } \\
\text { AAACTATCAAAATA }\end{array}$ & 64 \\
\hline $\begin{array}{l}\text { ico-AL-S2-anchor- } \\
30-017\end{array}$ & $\begin{array}{l}\text { TTACAACTAAAGGATTTACAAAATTATTTGCACGGACTGGAAACACTGGTC } \\
\text { ATAATCATGGTGG }\end{array}$ & 64 \\
\hline $\begin{array}{l}\text { ico-AL-S2-anchor- } \\
\text { 30-018 }\end{array}$ & $\begin{array}{l}\text { TTGAGTGAATAATTTTCCGAACCTCAAATATCAAGAACGGAAAACATCCTT } \\
\text { CATAGAAATTTCA }\end{array}$ & 64 \\
\hline $\begin{array}{l}\text { ico-AL-S2-anchor- } \\
30-019\end{array}$ & $\begin{array}{l}\text { TTGAAAGCGTGGCTATTATCCGGCTTAGGTTGGGTGGTAACGCTGCATGA } \\
\text { AGTAATCACGTTCT }\end{array}$ & 64 \\
\hline $\begin{array}{l}\text { ico-AL-S2-anchor- } \\
30-020\end{array}$ & $\begin{array}{l}\text { TTAACAACGCCCAGTAATCAATCGTCTGAAATGGGCATCATCTTGATTAAG } \\
\text { CTCATTAGGGTTA }\end{array}$ & 64 \\
\hline $\begin{array}{l}\text { ico-AL-S2-anchor- } \\
30-021\end{array}$ & $\begin{array}{l}\text { TTATTAAACCTTTTTTATTAGCCCAATAGGAACCCTGTAACCATAAGGCCAC } \\
\text { GTATTTTGCAAGC }\end{array}$ & 64 \\
\hline $\begin{array}{l}\text { ico-AL-S2-anchor- } \\
30-022\end{array}$ & $\begin{array}{l}\text { TTTGACAACAGGATTAGGCTCAGCAGCGAAAGACCTTTATCAGCGGCAGA } \\
\text { CTTGCCACCAAGTC }\end{array}$ & 64 \\
\hline $\begin{array}{l}\text { ico-AL-S2-anchor- } \\
30-023\end{array}$ & $\begin{array}{l}\text { TTCAGACCAGTGATATTCTGCTCATTCAGTGAATTAAGCATTTGGCGCATA } \\
\text { ATCTCGGAAACCT }\end{array}$ & 64 \\
\hline $\begin{array}{l}\text { ico-AL-S2-anchor- } \\
30-024\end{array}$ & $\begin{array}{l}\text { TTACAATAACAAAGTCAGAAGATGATGAAACAAAAACGAACCATAAAAAAG } \\
\text { CCTCCAAGATTTG }\end{array}$ & 64 \\
\hline $\begin{array}{l}\text { ico-AL-S2-anchor- } \\
30-025\end{array}$ & $\begin{array}{l}\text { TTTTTCATCTTCAAGATTTTACTAGAAAAAGCCTATTTTTCGTCCCCTTCGG } \\
\text { GGCGGTGGTCTA }\end{array}$ & 64 \\
\hline $\begin{array}{l}\text { ico-AL-S2-anchor- } \\
30-026\end{array}$ & $\begin{array}{l}\text { TTAGGCGGATCCCGGAATGTAGCGACAGAATCAACGTGTGAATCATTAGC } \\
\text { CTTGCGACCCTCGG }\end{array}$ & 64 \\
\hline $\begin{array}{l}\text { ico-AL-S2-anchor- } \\
30-027\end{array}$ & $\begin{array}{l}\text { TTATCAAAATCCCTCAGATGGTAATAAGTTTTAATTTGAGTCTCATTTTGCA } \\
\text { TCTCGGCAATCT }\end{array}$ & 64 \\
\hline $\begin{array}{l}\text { ico-AL-S2-anchor- } \\
30-028\end{array}$ & $\begin{array}{l}\text { TTAGAGATAAGAACCACCAAGAAAAGTAAGCAGACACCAGAAGCAGCATC } \\
\text { AGTGACGACATTAG }\end{array}$ & 64 \\
\hline $\begin{array}{l}\text { ico-AL-S2-anchor- } \\
30-029\end{array}$ & $\begin{array}{l}\text { TTATTACGCAAAGGTGGCTTATTTATCCCAATCCCCTGCATACGAAAAGAC } \\
\text { AGAATCTCTTCCA }\end{array}$ & 64 \\
\hline $\begin{array}{l}\text { ico-AL-S2-anchor- } \\
30-030\end{array}$ & $\begin{array}{l}\text { TTCCCAATAGATTCTAAGTCAACCGATTGAGGGAAACGCTGAATAGCAAA } \\
\text { GCCTCTACGCGATT }\end{array}$ & 64 \\
\hline $\begin{array}{l}\text { ico-FL-S2- } \\
\text { aptamer-anchor- } \\
001\end{array}$ & $\begin{array}{l}\text { GGAACCCTAAGAACGTAAGTTTTTCAAGAGTCTAAGCAAATTTGAGAGTTA } \\
\text { GGAATGT }\end{array}$ & 58 \\
\hline $\begin{array}{l}\text { ico-FL-S2- } \\
\text { aptamer-anchor- } \\
002\end{array}$ & $\begin{array}{l}\text { AGCATGTCAGCTGATAAGCAAACAGATATTCATTTGGGGCTTTGAGAGTTA } \\
\text { GGAATGT }\end{array}$ & 58 \\
\hline $\begin{array}{l}\text { ico-FL-S2- } \\
\text { aptamer-anchor- } \\
003\end{array}$ & $\begin{array}{l}\text { GATTAAGTGCCGGAAAATTACGCCAATGTGTAGGTAAAGATTTGAGAGTT } \\
\text { AGGAATGT }\end{array}$ & 58 \\
\hline
\end{tabular}




\begin{tabular}{|c|c|c|}
\hline $\begin{array}{l}\text { ico-FL-S2- } \\
\text { aptamer-anchor- } \\
004\end{array}$ & $\begin{array}{l}\text { TTGAGGGGTTAAATGTGGTGTAGACCAGCTTTTAAGCAACTTTGAGAGTTA } \\
\text { GGAATGT }\end{array}$ & 58 \\
\hline $\begin{array}{l}\text { ico-FL-S2- } \\
\text { aptamer-anchor- } \\
005\end{array}$ & $\begin{array}{l}\text { CGGGGAGATGTAAAGCCCTGTCGTAGCCGGAATTTTTTAATTTGGAGAGTT } \\
\text { AGGAATGT }\end{array}$ & 58 \\
\hline $\begin{array}{l}\text { ico-FL-S2- } \\
\text { aptamer-anchor- } \\
006\end{array}$ & $\begin{array}{l}\text { GATTTAGTAGAGCTTATCCATATATTTTTTGCGAGGAAGGGTTTGAGAGTTA } \\
\text { GGAATGT }\end{array}$ & 58 \\
\hline $\begin{array}{l}\text { ico-FL-S2- } \\
\text { aptamer-anchor- } \\
007\end{array}$ & $\begin{array}{l}\text { TAAAAATTCAAAGAATATACTTTTCAGAGGGGGTAATAGTTTTGAGAGTTA } \\
\text { GGAATGT }\end{array}$ & 58 \\
\hline $\begin{array}{l}\text { ico-FL-S2- } \\
\text { aptamer-anchor- } \\
008\end{array}$ & $\begin{array}{l}\text { CTAATCTACAGGAGAACAACCTTACTCGTATTAAATCCTTTTTGAGAGTTA } \\
\text { GGAATGT }\end{array}$ & 58 \\
\hline $\begin{array}{l}\text { ico-FL-S2- } \\
\text { aptamer-anchor- } \\
009\end{array}$ & $\begin{array}{l}\text { TTCCTGTGGACCTCCTGGTACCGACATCGCCATTAAAAATTTTGGAGAGTTA } \\
\text { GGAATGT }\end{array}$ & 58 \\
\hline $\begin{array}{l}\text { ico-FL-S2- } \\
\text { aptamer-anchor- } \\
010\end{array}$ & $\begin{array}{l}\text { CAAAAGAAATTGCCCTTGATGGTGTTTGATTAGTAATAACTTTGAGAGTTA } \\
\text { GGAATGT }\end{array}$ & 58 \\
\hline $\begin{array}{l}\text { ico-FL-S2- } \\
\text { aptamer-anchor- } \\
011\end{array}$ & $\begin{array}{l}\text { AATAATCGGACGACAAATATCCCAGTAATTCTCCACCGAGTTTGAGAGTTA } \\
\text { GGAATGT }\end{array}$ & 58 \\
\hline $\begin{array}{l}\text { ico-FL-S2- } \\
\text { aptamer-anchor- } \\
012\end{array}$ & $\begin{array}{l}\text { AAAGGGATACCACACCCGTTAGAACACGCTGCGACGTTAGTTTGAGAGTT } \\
\text { AGGAATGT }\end{array}$ & 58 \\
\hline $\begin{array}{l}\text { ico-FL-S2- } \\
\text { aptamer-anchor- } \\
013\end{array}$ & $\begin{array}{l}\text { ATTTCTTAAGAAAGGATTTAATTGTCAGCGGATCCAACAGTTTGAGAGTTA } \\
\text { GGAATGT }\end{array}$ & 58 \\
\hline $\begin{array}{l}\text { ico-FL-S2- } \\
\text { aptamer-anchor- } \\
014\end{array}$ & $\begin{array}{l}\text { CCGAAAGACTCAAATGAAGCAAAGTATTCATTCCAACCTATTTGAGAGTTA } \\
\text { GGAATGT }\end{array}$ & 58 \\
\hline $\begin{array}{l}\text { ico-FL-S2- } \\
\text { aptamer-anchor- } \\
015\end{array}$ & $\begin{array}{l}\text { GAACTGACCGCGAAACGCCGGAACCAGCGATTACCAGACGTTTGAGAGT } \\
\text { TAGGAATGT }\end{array}$ & 58 \\
\hline $\begin{array}{l}\text { ico-FL-S2- } \\
\text { aptamer-anchor- } \\
016\end{array}$ & $\begin{array}{l}\text { GATACATACCAGTCAGTCAGTTGAGCGGAACAAAGAAACCTTTGAGAGTT } \\
\text { AGGAATGT }\end{array}$ & 58 \\
\hline $\begin{array}{l}\text { ico-FL-S2- } \\
\text { aptamer-anchor- } \\
017\end{array}$ & $\begin{array}{l}\text { GATGAATAATCCTGATAAATAAAGGCAATTCAATAGATAATTTGAGAGTTA } \\
\text { GGAATGT }\end{array}$ & 58 \\
\hline $\begin{array}{l}\text { ico-FL-S2- } \\
\text { aptamer-anchor- } \\
018\end{array}$ & $\begin{array}{l}\text { AATTGAGGAACAGTGCTCAATATCTATTAACAATCGTCGCTTTGAGAGTTA } \\
\text { GGAATGT }\end{array}$ & 58 \\
\hline $\begin{array}{l}\text { ico-FL-S2- } \\
\text { aptamer-anchor- } \\
019\end{array}$ & $\begin{array}{l}\text { AAGAACGCAAGAGTCACTATATGTAGATTAAGGACAATATTTTGAGAGTTA } \\
\text { GGAATGT }\end{array}$ & 58 \\
\hline
\end{tabular}




\begin{tabular}{|l|l|c|}
\hline $\begin{array}{l}\text { ico-FL-S2- } \\
\text { aptamer-anchor- } \\
020\end{array}$ & $\begin{array}{l}\text { GGGACATTACCGCCAGCATTGGCATATCCAGACAGAGGCATTTGAGAGTT } \\
\text { AGGAATGT }\end{array}$ & 58 \\
\hline $\begin{array}{l}\text { ico-FL-S2- } \\
\text { aptamer-anchor- } \\
021\end{array}$ & $\begin{array}{l}\text { TGTAGCATCGCCACCCTAACACTGCCGCCACCGAGAACAATTTGAGAGTT } \\
\text { AGGAATGT }\end{array}$ & 58 \\
\hline $\begin{array}{l}\text { ico-FL-S2- } \\
\text { aptamer-anchor- } \\
022\end{array}$ & $\begin{array}{l}\text { AAGACTTTTATTCGGTAACGAGGGAGAGGCTGAGACTCCTTTTGAGAGTT } \\
\text { AGGAATGT }\end{array}$ & 58 \\
\hline $\begin{array}{l}\text { ico-FL-S2- } \\
\text { aptamer-anchor- } \\
023\end{array}$ & $\begin{array}{l}\text { TTGAGATGCAAGAGTACCCTGACGTGAGGCAGGTCAGACGTTTGAGAGTT } \\
\text { AGGATGT }\end{array}$ & 58 \\
\hline $\begin{array}{l}\text { ico-FL-S2- } \\
\text { aptamer-anchor- } \\
024\end{array}$ & $\begin{array}{l}\text { ACCTTTTTCCAAGTTAAAACAAAAGAGAATTAACTGAACATTTGAGAGTTA } \\
\text { GGAATGT }\end{array}$ & 58 \\
\hline $\begin{array}{l}\text { ico-FL-S2- } \\
\text { aptamer-anchor- } \\
025\end{array}$ & $\begin{array}{l}\text { ACGCTCAAAATACCGATCATATGCTGCGGGAGGTTTTGAATTTGAGAGTT } \\
\text { AGGAATGT }\end{array}$ & 58 \\
\hline $\begin{array}{l}\text { ico-FL-S2- } \\
\text { aptamer-anchor- } \\
026\end{array}$ & $\begin{array}{l}\text { GGTCATAGCATTAGCATTAGCGTCCCAGTAGCGTTGATATTTTGAGAGTTA } \\
\text { GGAATGT }\end{array}$ & 58 \\
\hline $\begin{array}{l}\text { ico-FL-S2- } \\
\text { aptamer-anchor- } \\
027\end{array}$ & $\begin{array}{l}\text { CCCCTGCCTGAATTTAGTGCCTTGTGGAAAGCACCACCGGTTTGAGAGTT } \\
\text { AGGATGT }\end{array}$ & 58 \\
\hline $\begin{array}{l}\text { ico-FL-S2- } \\
\text { aptamer-anchor- } \\
028\end{array}$ & $\begin{array}{l}\text { ACGGAATAATAATAAGCAAAGTTACCACCACCCTCAGAGCTTTGAGAGTTA } \\
\text { GGAATGT } \\
\text { aptamer-anchor- } \\
029\end{array}$ & $\begin{array}{l}\text { CCTTTACACGCTAACGAACGATTTTCCTGAATAGAAAATATTTGAGAGTTA } \\
\text { GGAATGT }\end{array}$ \\
\hline $\begin{array}{l}\text { ico-FL-S2- } \\
\text { aptamer-anchor- } \\
030\end{array}$ & $\begin{array}{l}\text { ACCGTCACCACAATCAAAATATTGAATAAGTTAGAAGGCTTTTGAGAGTTA } \\
\text { GGAATGT }\end{array}$ & 58 \\
\hline $\begin{array}{l}\text { anti-ico-FL-S2- } \\
\text { aptamer }\end{array}$ & $\begin{array}{l}\text { CATATCCGCGTCGCTGCGCTCAGACCCACCACCACGCACCACATTCCTAA } \\
\text { CTCTCAAA }\end{array}$ \\
\hline
\end{tabular}

